\title{
La bicicleta como modo de transporte que visibiliza el acceso desigual a la movilidad cotidiana: el caso de Santiago, Chile
}

\author{
Riding a bicycle as a means of transportation reveals the unequal access to
}

daily mobility: Santiago, a case study

\section{María Renee Salas*}

Recibido: 01 de mayo de 2018

Aceptado: 10 de diciembre de 2018

\section{Resumen}

El propósito de este artículo es el de visibilizar y caracterizar las diferenciadas barreras de acceso -financiera, sociocultural, espacial, temporal y de género- que los usuarios de la bicicleta enfrentan cotidianamente según lugar de residencia, grupo socioeconómico, grupo etario y género. Metodológicamente, se desarrolla un análisis con enfoque mixto en tres escalas: una macro, a través del reprocesamiento de datos de tipo cuantitativo (SECTRA, 2001, 2006, 2012) y otras, meso y micro, en base a estudios de casos: entrevistas, observación de terreno, espacialización y acompañamiento en el viaje. Los resultados muestran, la falta de una política de movilidad integral de escala metropolitana cuyo efecto, por una parte, no solo se traduce en la falta de continuidad y conectividad territorial, sino también favorece el acceso a la movilidad en bicicleta a quienes más conectados están y, por otra, no reconoce demandas particulares propias de cada territorio e invisibiliza a un ciclista antiguo de la periferia de la ciudad cuya movilidad en bicicleta ha sido y es una necesidad al acceder a la ciudad - por sus bajos ingresos, mayores niveles de obesidad y altos grados de exclusión social- y, por tanto, permanece siendo no acogido por la planificación urbana. Se concluye que el uso de la bicicleta reproduce, al igual que la red de transporte metropolitana, un modelo de desarrollo que profundiza acceso diferenciado a la movilidad en la metrópolis de Santiago, lo que dificulta avanzar hacia una movilidad urbana más sustentable y asequible para todos.

Palabras clave: acceso desigual a la movilidad, ciclista urbano, experiencia de viaje, movilidad urbana.

\begin{abstract}
This article's purpose is to make visible and typify the different access barriers -financial, sociocultural, spatial, temporal and gender- which bicycle riders face daily according to their gender, place of residence, their socioeconomic group, and age. Methodologically, it is developed in three scales: macro, through reprocessing quantitative data (such as SECTRA, 2001, 2006, 2012) and others; meso and micro, based on case studies: interviews, field observations, spatialization, and accompaniment. It is proposed to demonstrate lack of a metropolitan integral mobility policy whose effect, first, not only results in lack of continuity and territorial connectivity but also favors access to bicycle mobility to those who are already most connected and second, it does not recognize particular demands of each territory and makes invisible an old cyclist from the outskirts of the city whose bicycle mobility has been and still is a need when accessing the city - due to low income, higher levels of obesity and high degrees of social exclusion- and, therefore, is still not considered by urban planning. The use of the bicycle translates, just like the metropolitan transport network, into a development model that deepens differentiated access to mobility in the metropolis, which makes it difficult to move towards a more sustainable and accessible urban mobility.
\end{abstract}

Keywords: commute experience, unequal access to mobility, urban mobility, urban cyclist.

\section{* Filiación: Santiago de Chile, Chile. Contacto: mariasalas@ug.uchile.cl}

El manuscrito es parte de los resultados de la tesis de magíster de la autora El uso de la bicicleta: reproductor del acceso desigual a la movilidad cotidiana urbana: visibilizar al ciclista tradicional que reside y se desplaza en la periferia sur de La Metrópolis; una oportunidad hacia ciudades más inclusivas. Caso de Santiago. Magíster en Urbanismo, Universidad de Chile, 2018.

Cómo citar: Salas, M.R. (2018). La bicicleta como modo de transporte que visibiliza el acceso desigual a la movilidad cotidiana: el caso de Santiago, Chile. Revista de Urbanismo, 39, 1-26. https://doi.org/10.5354/0717-5051.2018.49157 


\section{Introducción}

El dominio que ejerce la movilidad urbana y las infraestructuras necesarias para su desarrollo ha derivado en la adaptación de la morfología de las ciudades en función de las necesidades del automóvil, aunque este sea uno de los principales causantes de contaminación del planeta. El automóvil, además de producir otros efectos adversos como la emisión de $\mathrm{CO}_{2}$, contaminación acústica e incremento en la congestión, entre otros, es un factor importante de deterioro de la calidad de vida ciudadana (Banco Mundial, 2017).

En tal sentido, ha cobrado gran importancia la movilidad no motorizada como forma de traslado desde una aproximación más humana, saludable, económica, eficiente y limpia para el medioambiente. Esta opción propende no solo a desincentivar el uso del vehículo particular motorizado, sino también aporta sustentabilidad desde la dimensión ambiental, minimiza emisiones desde la dimensión social, mejora la igualdad, la cohesión y la inclusión, específicamente en cuanto a personas de menores ingresos, mujeres, niños y adultos mayores, los que enfrentan múltiples formas de discriminación. Finalmente, desde la dimensión económica, existen múltiples estudios que evidencian los modos no motorizados como transporte económicamente rentable.

En el marco de Chile, la Política Nacional de Desarrollo Urbano (en adelante, PNDU)) establece dos objetivos asociados a la movilidad urbana que inciden en el uso de la bicicleta y relevan el propósito de este artículo: garantizar el acceso equitativo a los bienes públicos urbanos y fomentar el tránsito peatonal y el uso de la bicicleta a través de normativas, interrelación armónica entre los modos y uso compartido del espacio público (PNDU, 2014).

El Área Metropolitana de Santiago (en adelante AMS) -en parte de manera contradictoria- responde a una ciudad cuyo crecimiento expansivo ha transformado, para algunos, la cercanía y la proximidad a los bienes y servicios en un lujo y un privilegio, y ha ido consolidando un patrón diario que consiste en largos viajes que consumen parte importante de tiempo, presupuesto y salud de las personas, afectando negativamente su calidad de vida. Esta problemática de la movilidad urbana refleja una accesibilidad diferenciada a los bienes y servicios, además de oportunidad desigual de integración social en base a las diversas dinámicas asociadas a las experiencias de viajes (Gutiérrez, 2012).

Sumado al ya conocido problema de convivencia vial entre la bicicleta y el total de modos que se desplazan al interior de la ciudad, siendo los principales afectados la calidad de los viajes y la función del espacio de uso público, se observa también, foco del presente artículo, una planificación asociada al uso de la bicicleta que se ha traducido en planes intercomunales adosados a las vías intercomunales y ejes de transporte público, sin atender la reproducción desigual en la accesibilidad a la movilidad en bicicleta como modo de transporte en zonas más pobladas y demandantes de viajes por motivos de desplazamiento laboral y educativo. Ello en una ciudad que se caracteriza por la concentración del empleo y la educación distante de los mayores núcleos de residencia (French-Davis, López y Arriagada, 2012; Rodríguez, 2016).

La movilidad cotidiana con enfoque en el ciclista, entendida como la estructura y la experiencia de viaje que permiten a los habitantes acceder a los bienes y servicios de la ciudad de manera segura, planificada y de calidad, se observa deficitaria en su planificación, cobertura territorial y en la experiencia y la calidad de viaje, como efecto de una planificación centrada en el transporte más que en la movilidad urbana. La sucesión de proyectos de ciclovías en tramos parciales e inconexos y principalmente en comunas con capacidad de inversión adolece de la reproducción estandarizada de una infraestructura para la bicicleta, que se ha implementado con una mirada sectorialista en base a variables tradicionales del transporte que privilegian la conectividad y tiempos de viaje motorizado, y sin la debida atención a las demandas locales de la ciudad como tampoco a la estructura y la experiencia de viaje.

Este artículo busca aproximarse al uso de la bicicleta como modo de transporte cotidiano asociado al trabajo y el estudio, bajo la hipótesis que el uso de este vehículo, ligado a los ejes viales del actual sistema de transporte y a la falta de atención a las demandas locales, reproduce el acceso desigual a la movilidad cotidiana, e incide a escala de usuario en diferenciadas estructuras, experiencias y calidad de viaje. Si el propósito de la movilidad urbana no son los desplazamientos sino la capacidad de acceder a los recursos de la ciudad (Gutiérrez, 2012), entonces la 
accesibilidad desigual a la movilidad en bicicleta profundiza el acceso diferenciado a la ciudad.

\section{Antecedentes teóricos conceptuales}

En la planificación urbana existe un déficit asociado al uso de la bicicleta, expresado a escalas macro y meso en desigualdad de acceso a la movilidad, y a escala micro o local, en la falta de atención a las barreras de accesibilidad asociadas a la estructura y la experiencia de viaje como enlace clave entre oferta y demanda. Con el propósito de visibilizar estas condiciones, los antecedentes teóricos enfatizan el concepto de movilidad urbana, ligado a la escala metropolitana y con enfoque en el ciclista urbano como parte de un modelo de tipo expansivo y políticas urbanas del transporte. El segundo concepto de estudio, ligado a las escalas meso y micro, es la accesibilidad desigual a dicha movilidad, a causa de una planificación y un diseño que reproducen los lineamientos y trazados de un transporte al cual no todos los sectores socioeconómicos, grupos etarios y de género tienen igual acceso.

En las actuales ciudades globalizadas, la movilidad constituye un componente articulador del territorio y se establece una:

[A]sociación de carácter recíproco entre el modelo de urbanización y el de desplazamiento territorial, en torno a una lógica locacional cuya distribución territorial de la población, de las actividades, de los sistemas de transporte y demás soportes de las funciones urbanas es la variable explicativa del desplazamiento territorial, y todos ellos son entendidos como lugares o puntos en el territorio" (Gutiérrez, 2012, p. 65).

El modelo urbano de tipo expansivo ha roto los vínculos de proximidad y ha sido sustituido por vínculos de conexión a muy diferentes niveles. Esta situación consolida un modelo urbano como rehén de la movilidad (Hall, 1996).

\footnotetext{
${ }^{1}$ Se entiende por exclusión asociada a la movilidad, la existencia de individuos que están fuera del modelo de movilidad, motivo por el cual se ven privados de satisfacer sus necesidades asociadas a bienes $y$ servicios (Rodríguez, 2008).
}

Una parte importante de la población del AMS es móvil, concepto que abarca a todos aquellos que se desplazan intra e intercomunalmente por motivos de trabajo o estudio. Esta movilidad es más frecuente entre los asalariados y en el mercado de trabajo formal, además de corresponder a un atributo típico de los estratos socioeconómicos más bajos. Aunque la falta de movilidad pudiese significar menos tiempo dedicado al transporte, también representa exclusión social ${ }^{1}$. Los estratos más bajos son los que tienen menores opciones de utilizar la migración como medio para insertarse en las oportunidades que ofrecen las ciudades, principalmente los centros urbanos que generan la mayor cantidad de empleos y servicios para la población (Miralles-Guasch y Cebollada, 2003).

La planificación asociada a la movilidad urbana, funcionalista y vinculada al concepto de transporte ${ }^{2}$ enfrenta a un modelo que articula una ciudad fragmentada, creciente y desigual, donde el espacio público se ha transformado en espacio conectivo, con la pérdida de funciones de sociabilidad y con la adaptación formal a las velocidades impuestas por los transportes mecánicos (Miralles-Guasch y Cebollada, 2003). Los efectos y externalidades negativas de esta situación están, en la circulación y el uso masivo del transporte privado, que no solo se ha posicionado como protagonista del espacio público, desplazando al peatón, sino que además ha incrementado la exclusión social, y por otra parte ha disminuido la accesibilidad, variable que permite ejercer el derecho a la ciudad.

Movilidad urbana y accesibilidad desigual. Si el territorio del AMS, bajo el modelo de desarrollo urbano imperante, está fragmentado y distante entre las diversas locaciones, y no es homogéneo, sino que presenta acentuadas desigualdades socio territoriales, los estudios de movilidad debieran investigar la forma en que los distintos subterritorios participan de esa fragmentación por sobre el hecho de implementar una infraestructura estandarizada (Cebollada, 2008).

\footnotetext{
2 El concepto "transporte" considera todos los modos, servicios e infraestructura que posibilitan el desarrollo de la movilidad individual (SECTRA, 2014).
} 
Planificar e implementar una oferta asociada a la movilidad requiere definir igualdad versus equidad. El concepto de igualdad parte de la idea de que todas y todos somos iguales en derechos y oportunidades y, por tanto, para efectos de la movilidad, la igualdad se refiere a la oportunidad y a la posibilidad que todas y todos tengamos acceso a esta. Por su parte, el concepto de equidad se refiere a un principio ético y de justicia. Se trata de tener la oportunidad de acceder a la movilidad desde las respectivas necesidades y requerimientos, heterogéneos y dependientes de lugar de residencia, edad, cultura y política, entre otros. En tal sentido, Miralles-Guasch \& Cebollada (2003) afirma que la relación entre exclusión social y movilidad no se establece por la falta de oportunidades sino por la falta de acceso a dichas oportunidades en términos de equidad social.

Miralles-Guasch \& Cebollada (2003), consideran tres variables fundamentales que determinan la oportunidad de acceder a la movilidad: cobertura territorial del transporte, amplitud horaria y costo. Centrándose en la movilidad en bicicleta y de acuerdo con lo planteado en la EOD (SECTRA, 2012), la variable costo (cero pesos) y la libertad horaria juegan un papel relevante en la toma de decisiones de los sectores más vulnerables. Por tanto, la bicicleta no solo representaría una oportunidad eficiente de acceder a la ciudad, sino también implicaría una oportunidad que podría propender a la cohesión social, entendiéndola como la capacidad de disminuir, especialmente en los sectores más vulnerables, la cantidad de territorios desprovistos de accesibilidad (Cebollada, 2008).

\section{Caracterización de la demanda, ciclista urbano con propósito trabajo y estudio}

Con el fin de caracterizar al actual ciclista urbano del AMS en términos de demanda y uso, es decir, accesibilidad a la movilidad y su relación con la oferta ciclovial, se sistematiza los resultados obtenidos en el PMCGS ${ }^{3}$. En general, los usuarios son propietarios de la bicicleta (98\%) y tienen acceso a estacionamiento tanto en el origen como en el destino, siendo menor en este último $199 \%$ versus $84 \%$ ). Los viajes en bicicleta en el periodo punta de la mañana son principalmente por razones de trabajo. Se trata de desplazamientos frecuentes, cuyo tiempo de recorrido promedio es de 29 minutos. Los motivos por los que los usuarios utilizan la bicicleta, en orden de importancia, son: es más barato, se demora menos, por deporte/salud, comodidad y porque no contamina. Además, el $86 \%$ declara usar la bicicleta como modo de transporte, y el $58 \%$ de ellos la usa de esta forma hace más de un año. La antigüedad promedio con este uso es de 4,2 años. El $40 \%$ de los usuarios declara usarla a modo recreativo (SECTRA, 2013).

En cuanto a la percepción de seguridad al andar en bicicleta, se observa que los usuarios sienten mayor inseguridad frente a la ocurrencia de actos vandálicos que ante la posibilidad de sufrir accidentes, aunque el $36 \%$ declara haber tenido algún accidente, siendo la principal causa de este un vehículo motorizado. La percepción de inseguridad es mayor cuando se circula por lugares distintos a ciclovías, y es levemente mayor en mujeres que en hombres. La experiencia de viaje es una de las expresiones que probablemente refleja las desigualdades de acceso a la movilidad y, por tanto, a la ciudad (Jirón, 2007). La imagen de ciudad sugiere distinciones y relaciones ante las cuales el observador o usuario escoge, organiza y da significado, y por tanto asigna experiencia en un continuo estado de interacción espacio-observador, de manera parcial y fragmentada, en que todos los sentidos se encuentran en acción (Lynch, 1998).

No es posible pensar en la movilidad y la experiencia de viaje sin la interdependencia entre estos, un espacio específico y un usuario o grupo social definido. La movilidad y la experiencia de viaje se convierten en todo lo que precede, acompaña y prolonga este desplazamiento, incluidas las estrategias, que cambian según las personas que la practican. Por tanto, las desigualdades de accesibilidad a la movilidad no solo se relacionan con el tiempo y el espacio en que habitan, sino también, en el análisis de las experiencias de viaje que visibilizan movilidades diferenciadas, es decir la experiencia de viaje es muy distinta dependiendo de quien la vive (Jirón, 2012).

Finalmente, desde la mirada del transporte la movilidad urbana se aborda como origen y destino, mientras que desde la mirada de la experiencia de viaje se

3 PMCGS: Plan Maestro de Ciclovías del Gran Santiago. 
reconoce la movilidad desagregada y cronológica. Gutiérrez (2012), señala que en un viaje hay tres momentos capaces de conformar la experiencia:

- Momento "previaje", vinculado a la decisión, la planificación y la organización.

- Momento "viaje", vinculado al trayecto entre el lugar de origen y de destino.

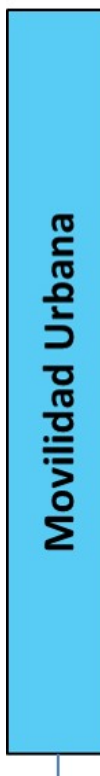

\section{TRANSPORTE}
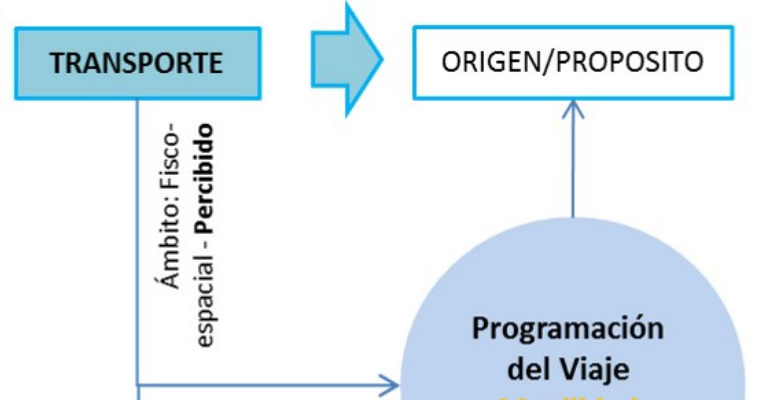
.

- Momento "posviaje", vinculado a la realización de la actividad final del recorrido.

En la Figura 1, se detalla, desde esa perspectiva cronológica, los componentes subjetivos y objetivos que facilitan o dificultan la experiencia y la calidad de viaje del ciclista urbano.

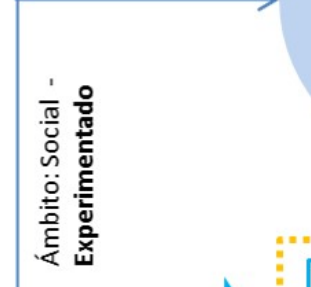

\section{Programación} del Viaje
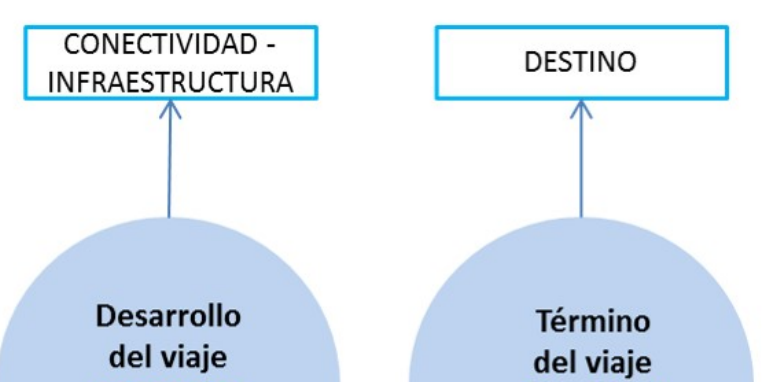

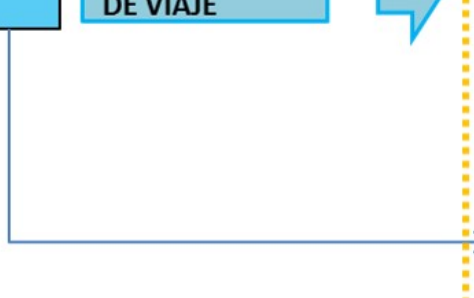




\section{Metodología}

Este artículo aborda los objetivos de investigación en base a una metodología mixta, de carácter cuantitativo y cualitativo. Se busca develar, a escala macro, meso y micro, la accesibilidad desigual a la movilidad cotidiana del ciclista urbano, con énfasis en visibilizar un ciclista tradicional, localizado principalmente en la periferia sur de Santiago y que no ha sido debidamente atendido por la planificación urbana.

La primera fase de estudio estuvo referida al análisis bibliográfico y de antecedentes estadísticos que permitió consolidar un marco teórico como fundamento, desarrollo conceptual y eje conductor del estudio. En una segunda fase y ligado al primer objetivo específico, se realiza la sistematización y el reprocesamiento de datos estadísticos del informe de la Encuesta Origen Destino (EOD) (SECTRA, 2001, 2006, 2012) y PMCGS. De la EOD, se utilizan datos de escala metropolitana tales como número de población, grupo socioeconómico, oferta ( $\mathrm{km}$ de infraestructura especializada) y demanda (número total de viajes por comuna). En cuanto al PMCGS, se utiliza una muestra de 641 encuestas a usuarios de la bicicleta que recoge características de viaje, origen-destino, propósito y tiempo de viaje, grupo etario y razones para usar este medio de transporte, entre otros.

En una tercera fase, ligado a las escalas meso y micro, y con el propósito de responder al segundo objetivo específico, se seleccionan -a partir de los resultados obtenidos en la fase 2 - los dos casos más representativos de un universo de 7 casos desarrollados en el estudio de tesis: un caso de la comuna de Maipú y otro del cono oriente, con la finalidad de visibilizar y contrastar, desde la estructura y la experiencia de viaje, la accesibilidad desigual a la movilidad en bicicleta en su relación con lugar de residencia, grupo socioeconómico, edad y género.
Los dos casos seleccionados tienen dos propósitos. Por una parte, visibilizar las barreras de accesibilidad a la movilidad -financiera, sociocultural, espacial y temporalque se experimentan cotidianamente al momento de acceder a la bicicleta y, por otra, visibilizar cómo dichas barreras inciden de manera diferenciada según lugar de residencia, nivel socioeconómico, edad y género.

Los ciclistas urbanos residentes en la comuna de Maipú, representantes del sector sur del Gran Santiago, corresponden a los antiguos ciclistas urbanos que utilizan la bicicleta como modo de transporte cotidiano y cuyos desplazamientos coinciden, hasta la EOD 2006, con los sectores de mayor concentración de viajes en bicicleta, menores ingresos y menor implementación de infraestructura especializada.

Con la finalidad de expresar o no el desigual acceso a la movilidad en bicicleta, mediante la técnica de contraste se explora viajes de ciclistas urbanos, nuevos usuarios, de sectores más acomodados del nororiente del Gran Santiago, caracterizado por su condición de "Centro Extendido"4 y por presentar dinámicas de movilidad asociadas principalmente a los desplazamientos de las elites por motivo de trabajo y ligadas al centro histórico de la ciudad. La EOD 2012 muestra cómo dicha dinámica es reproducida por la movilidad en bicicleta, siendo estas las comunas con mayor implementación de infraestructura (ciclovías) y actualmente el sector con mayor demanda de viajes en bicicleta, lo que vendría a confirmar el peso que tiene la infraestructura como catalizador de una nueva demanda.

Con el propósito de visibilizar a modo referencial lo expuesto, se selecciona los siguientes casos de estudio:

\footnotetext{
${ }^{4}$ Las elites, ubicadas en el cono oriente de Santiago, también muestran exclusión social al trabajar bajo la noción de "hábitat intermunicipal de las elites", las cuales se desplazan por motivos de trabajo en distancias
}

cortas y ligadas al centro histórico, el llamado "Centro Extendido" (Santiago Centro, Providencia y las Condes) (Rodríguez, 2008). 


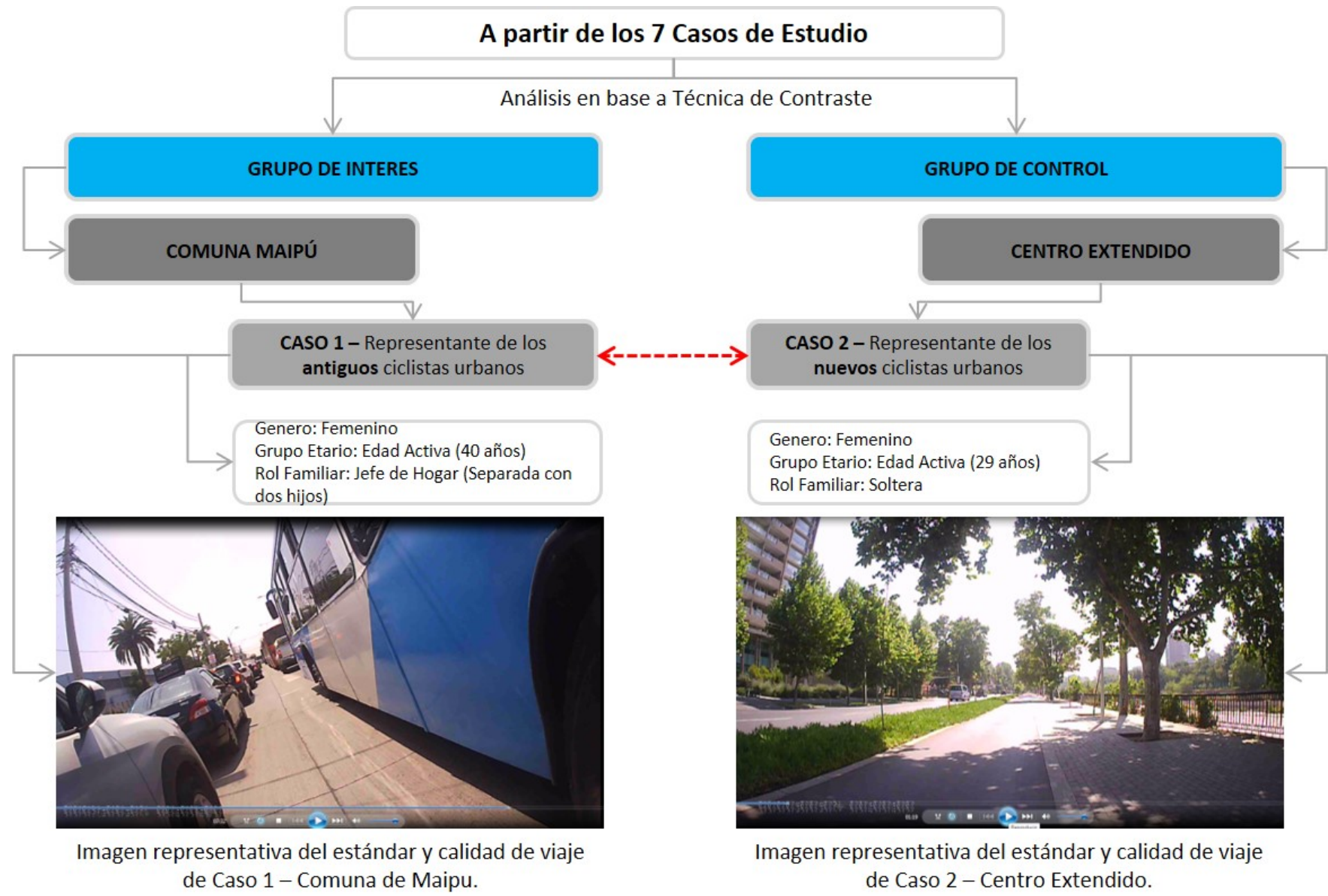

Figura 2. Selección de casos de estudio y análisis en base a técnica de contraste.

Fuente: Elaboración propia con base en entrevistas y acompañamiento de viaje cotidiano.

Para la caracterización de la estructura, la experiencia y la calidad de viaje de ambos casos de estudio, se sistematizan las barreras de tipo financiero, sociocultural, espacial, temporal y de género. Luego se observa mediante entrevistas semiestructuradas, reuniones de trabajo en base a planimetría, creación de confianza y acompañamiento en el viaje- las estrategias en que estas personas se desenvuelven respecto a la movilidad cotidiana en bicicleta según sector territorial.

Se señalan las barreras de accesibilidad a la movilidad en bicicleta que serán analizadas en ambos casos de estudio: 


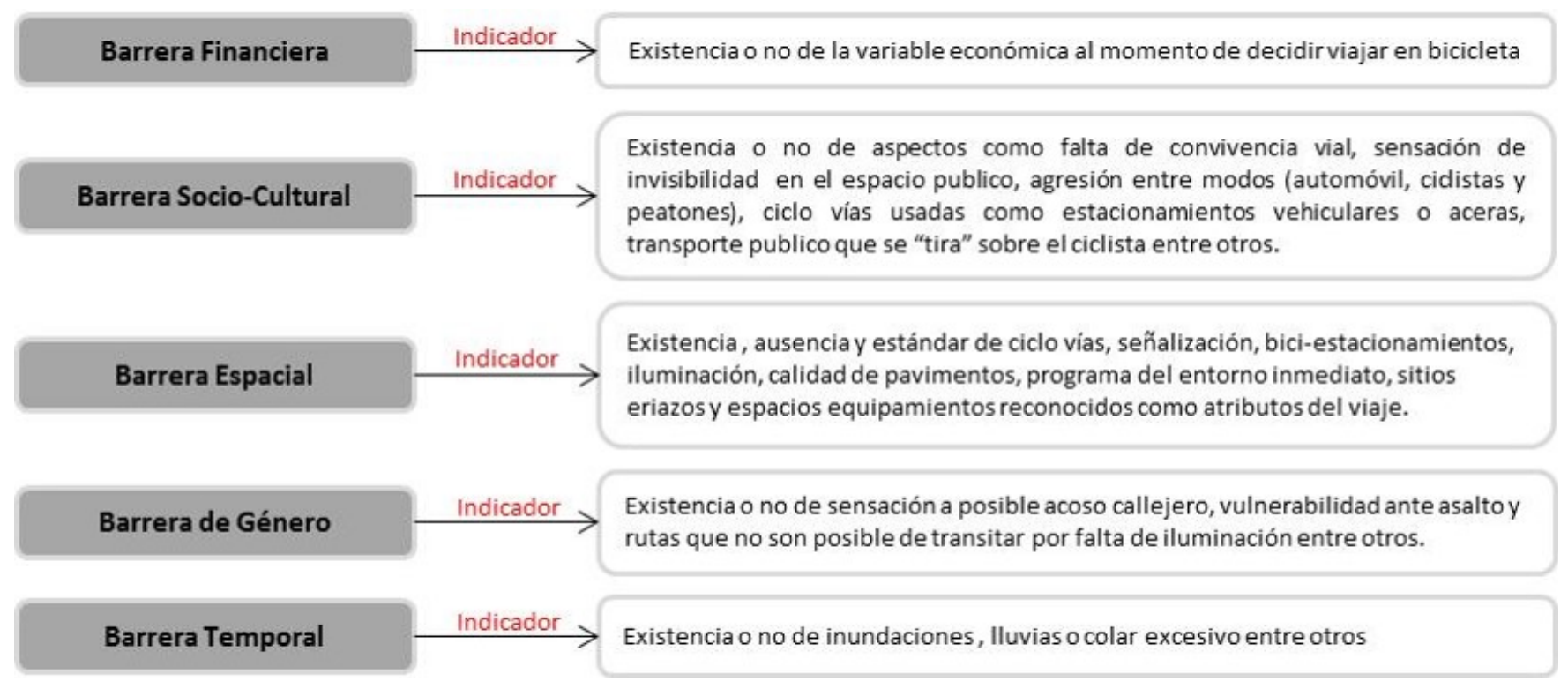

Figura 3. Barreras de accesibilidad y definición de indicadores.

Fuente: Elaboración propia con base a entrevistas y experiencia de la autora.

La identificación de barreras aparece y desaparece a lo largo de un viaje, determinando la experiencia y calidad de este. La clasificación de tipos de experiencia de viaje es determinada en base a lo recogido en entrevistas y experiencia de la autora: el cuerpo adquiere un determinado estado frente a los diversos estímulos del entorno, ya que la movilidad en bicicleta tiene la particularidad de estar en permanente relación con el entorno urbano (temperatura, olores, calidad del espacio público, contacto con los otros modos y esfuerzo físico, entre otras variables). Se adjunta el método de análisis para cada caso de estudio: 


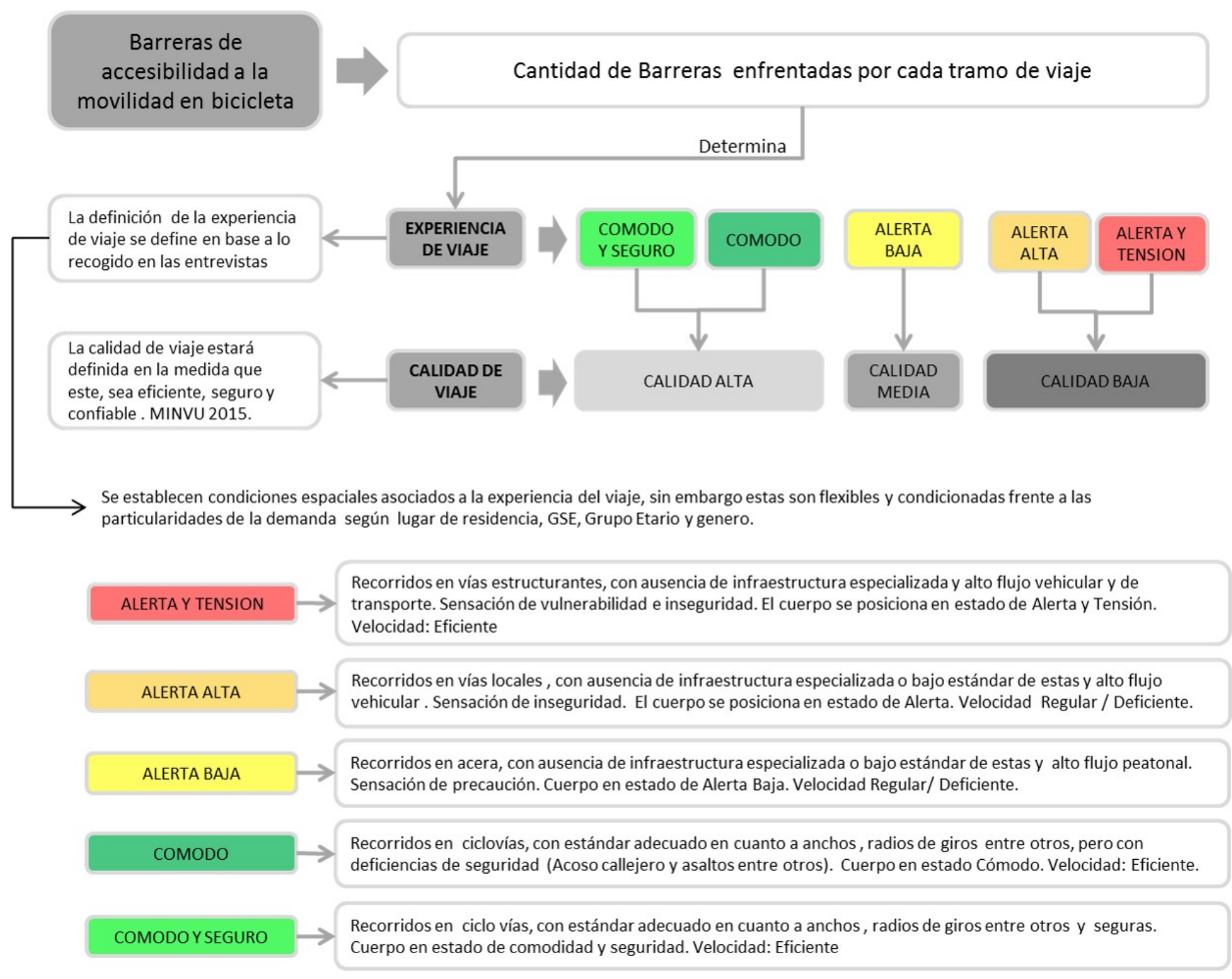

Figura 4. Metodología de análisis referido a la experiencia de viaje. Escalas meso y micro.

Fuente: Elaboración propia con base a entrevistas y experiencia de la autora.

\section{Desarrollo y presentación de resultados}

\section{Escala Macro - Acceso Desigual a La Movilidad Urbana}

Se analizan cuatro factores que, en sí mismos e interrelacionados, determinan la posibilidad de acceder a la movilidad cotidiana en bicicleta como modo de transporte ${ }^{5}$ y con ello, a la ciudad. Se considera como $\mathrm{Al}^{6}$ las 34 comunas incluidas en el PMCGS (SECTRA, 2012).

\footnotetext{
5 En adelante "movilidad cotidiana en bicicleta como modo de transporte" será señalada como MCBT.
}

\section{Factor $N^{\circ} 1$ : Acceso a la infraestructura.}

Variable: Km de ciclovía por comuna año 2016 y proyectada al año 2025. Este factor devela la relación entre los requerimientos de la demanda y la atención de la planificación. La demanda actual por comuna es determinada por los viajes en bicicleta en horario punta de la mañana (7:00-9:00 h) por motivos de trabajo y estudio. La demanda potencial es la definida por el estudio "Investigación, factibilidad y gestión de concesión de bicicletas públicas" (GORE, 2012), que determina el rango de edad de usuarios entre 18 y 65 años.

\footnotetext{
${ }^{6}$ En adelante Al estará referida a Área de Influencia.
} 


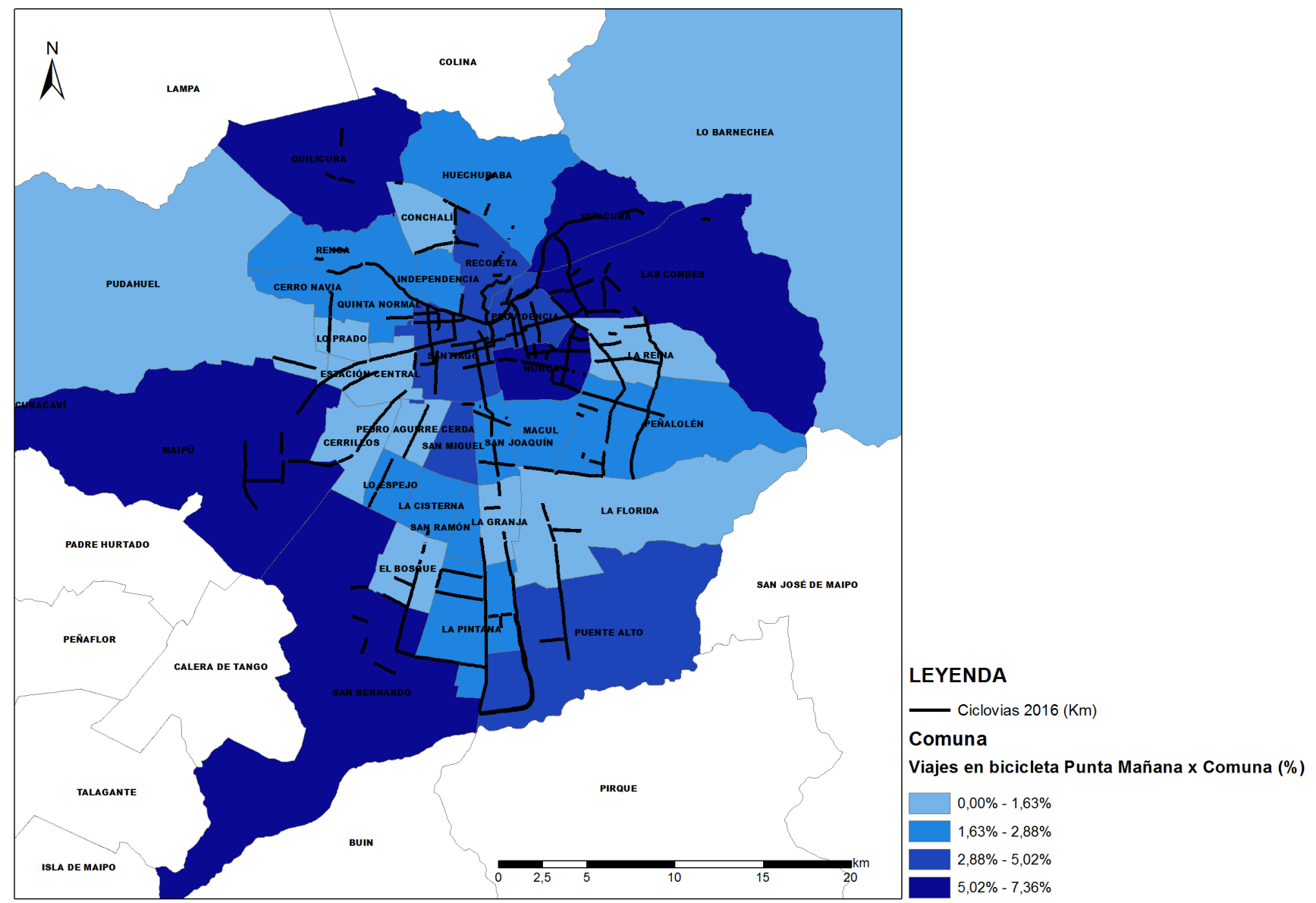

Figura 5. Área de influencia, oferta por macrozona y comuna / año 2016 y proyectada.

Fuente: Elaboración propia a partir de a EOD 2012.

La oferta implementada por comuna al año 2016 muestra que la macrozona nororiente es la de mayor captura de oferta ( $\mathrm{km}$ de ciclovías), seguida por el poniente, luego las macrozonas sur y suroriente, y por último, la norponiente, con la menor cantidad de infraestructura asignada. En caso de implementarse el total del PMCGS al año 2025, dicha desigualdad se mantendría en el tiempo.
Una vez identificada la desigualdad de infraestructura existente por comuna, actual y proyectada, se revisa la cantidad actual de $\mathrm{km}$ por comuna, para identificar promedio y porcentaje de infraestructura con respecto al total. El siguiente gráfico determina $8.50 \mathrm{~m}$ como promedio de infraestructura actual por comuna. Un $65 \%$ de las comunas está por debajo de este promedio, siendo Santiago Centro la con mayor implementación de ciclovías, con $36.45 \mathrm{~km}$, lo que representa el $12,6 \%$ del total de la red actual, y las comunas de menor crecimiento, Lo Barnechea y Macul, con $0 \mathrm{~km}$ proyectado. 


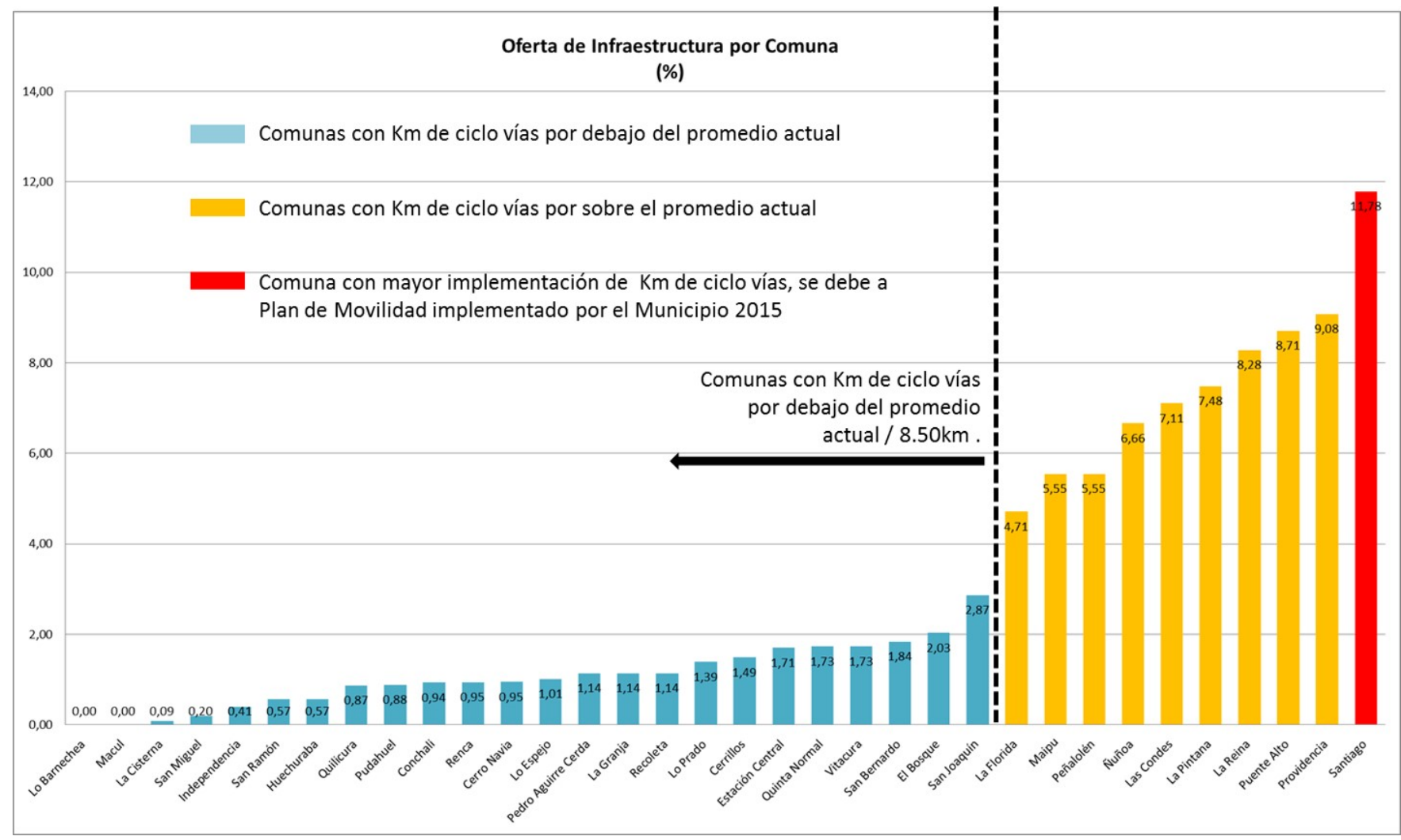

Figura 6. Porcentaje de oferta de infraestructura (ciclovías) por comuna, año 2016.

Fuente: Elaboración propia a partir de EOD 2012.

La extensión territorial del plan de ciclovías no es homogénea sino, por el contrario, se concentra principalmente en las comunas del Centro Extendido, capturando el $33 \%$ de la infraestructura existente. Destacan a su vez, con incremento de oferta, San Joaquín, Maipú, La Florida, Peñalolén y La Pintana, que coinciden además con las de más altas poblaciones de la conurbación. Sin embargo, y aunque no es el foco de análisis, cabe señalar que, si bien estas comunas han experimentado un aumento de $\mathrm{km}$ en sus redes, en su gran mayoría son de muy bajo estándar, siendo deficitarias en eficiencia, seguridad y funcionalidad. Por su parte, Puente Alto se encuentra entre las comunas que poseen una mayor cantidad de $\mathrm{km}$ de ciclovías (25 km) aunque sólo entregan conexión norte-sur, siendo, además, de muy bajo estándar. Las restantes 23 comunas se encuentran en contraposición, aportando actualmente un muy bajo porcentaje de $\mathrm{km}$ a la red de ciclovías.

Variable demanda actual. Para hablar de desigualdad de accesibilidad a la MCBT, es necesario cruzar la oferta con la demanda actual en cuanto a número de viajes en bicicleta por motivos de trabajo o estudio, en horario punta de la mañana. Se destaca que el $87 \%$ del total de los viajes en bicicleta en dicho horario son por motivos de trabajo o estudio. 


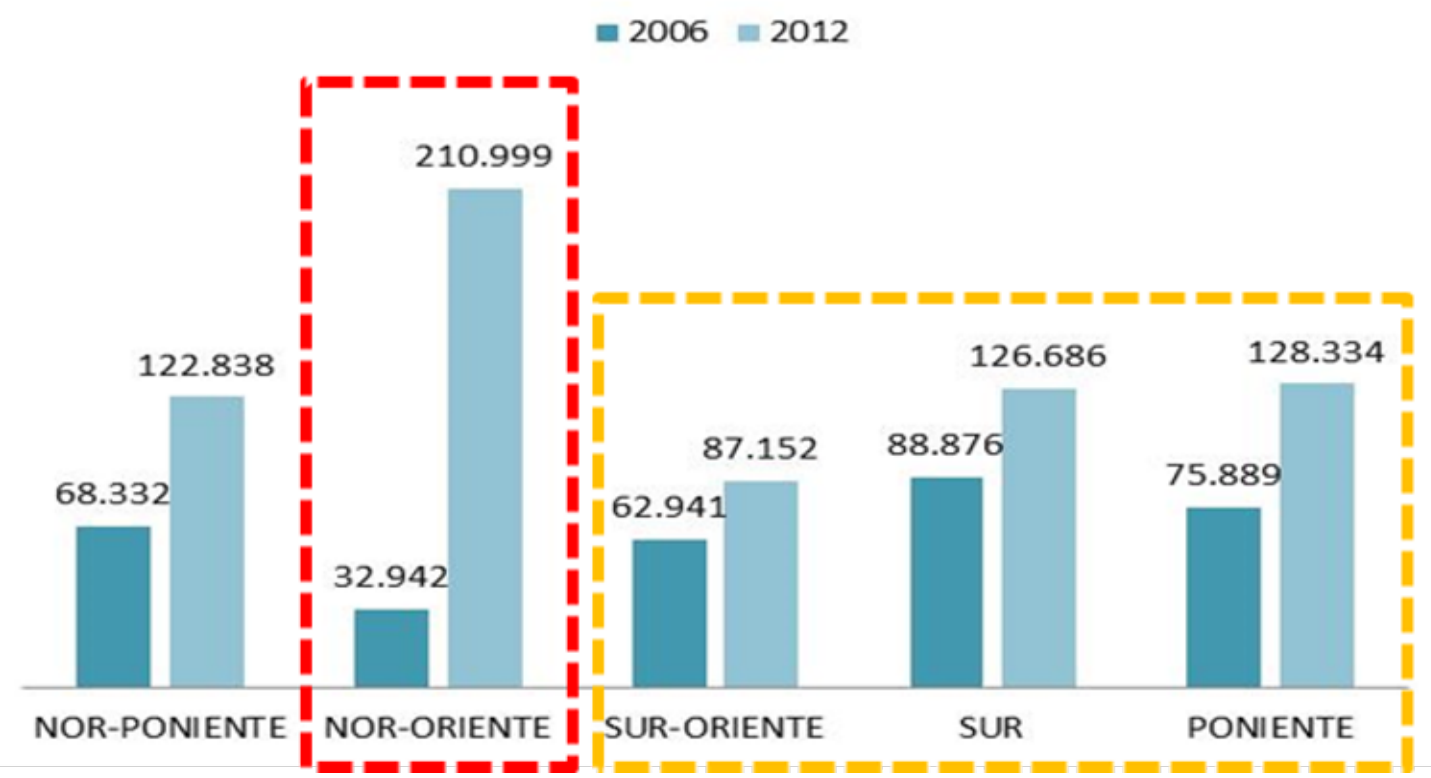

Figura 7. Número de viajes en bicicleta por macrozona.

Fuente: Elaboración propia en base a EOD 2006 y 2012.

Al año 2006 se observa una mayor demanda de viajes en bicicleta en el sector sur de la ciudad, lo que identificaremos como antiguos usuarios de la bicicleta. Al 2012, dicha demanda se ha incrementado a pesar de la falta de implementación de infraestructura. Lo anterior cambia drásticamente en la EOD 2012, observándose una explosión de la demanda en el sector nororiente, correspondiente a una tasa de crecimiento del $541 \%$ respecto a la registrada en 2006. Se estima que esto sucede debido al importante incremento de la oferta, lo que confirma la capacidad catalizadora de incentivar una nueva demanda.

En la figura siguiente, se georreferencia y espacializa la relación desigual entre la oferta (ciclovías) y la demanda por comuna, destacando las comunas de Maipú y Las Condes. 


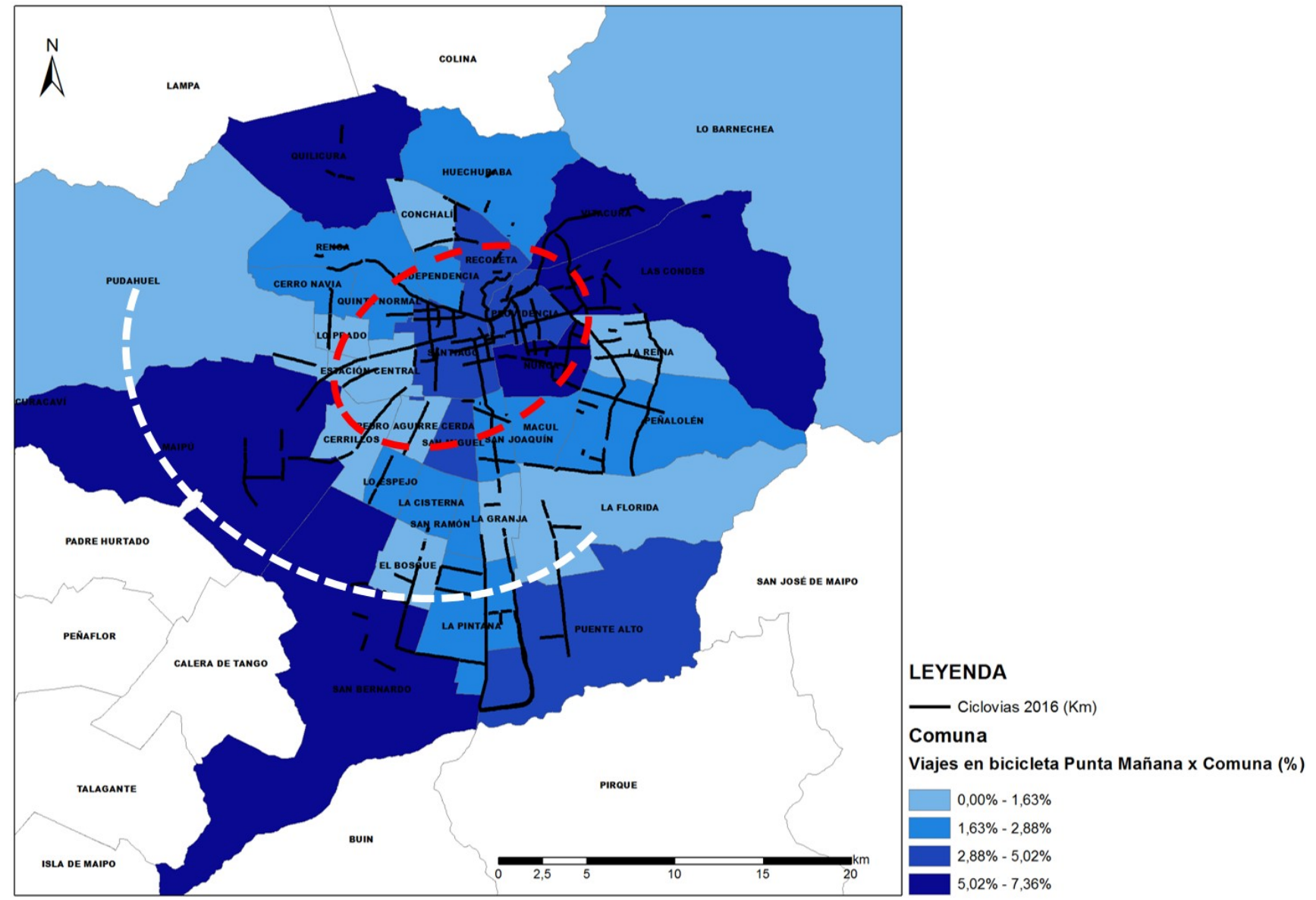

Figura 8. Viajes PM por motivo de trabajo y estudio según lugar de residencia.

Fuente: Elaboración propia en base a EOD 2012

Variable demanda potencial. Para dimensionar la accesibilidad a la movilidad en bicicleta al término del PMCGS al año 2025, se estimó:

- Implementación futura del PMCGS al año 2025.

- Demanda potencial: población activa entre 15 y 59 años. Estudio "Investigación, factibilidad y gestión de concesión de bicicletas públicas" (GORE, 2012).

Al observar la demanda potencial por macrozona y comuna (año 2025), se mantendría el sector nororiente como el de mayor asignación de infraestructura por habitante, en circunstancias que se prevé que la mayor concentración de la demanda se mantendría en el sector sur.

A escala comunal, el $44 \%$ del total de las 34 comunas estaría al año 2025 por sobre el promedio proyectado (0,33 km de ciclovía/demanda potencial). Sin embargo, este promedio responde a una muestra de la distribución desigual de la infraestructura por comuna. Destacan con la mayor oferta al año 2025 Providencia y La Reina de la macrozona nororiente, y Macul de la macrozona suroriente, en circunstancias que la mayor demanda por viajes en bicicleta se concentraría en La Florida, Maipú, Puente Alto y Santiago Centro.

Factor 2: Acceso a la movilidad según lugar de residencia.

Variable grupo socioeconómico (GSE). El lugar de residencia está asociado al GSE y su relación con la demanda de viajes en bicicleta por trabajo o estudio.

El acceso al transporte y la movilidad cotidiana se expresan de manera diferenciada según lugar de residencia y GSE, siendo la movilidad en bicicleta un reflejo de una accesibilidad desigual a la ciudad. Mientras para algunos, dicha movilidad es una opción, para otros se torna una oportunidad de acceder a los bienes y servicios, 
dada la falta de conectividad y las largas distancias a recorrer entre la residencia y el trabajo, además de la posibilidad de ahorro económico, principal motivo este último para usar la bicicleta (SECTRA, 2006, 2012).

A partir de la EOD 2001, se observa mayor demanda por el uso de la bicicleta como modo de transporte en el sector sur y, en general, en toda la periferia de la ciudad. Este dominio se ha mantenido e incrementado al año 2012, pese a la falta de atención por parte de la planificación y la implementación de infraestructura. Las comunas que cuentan con mayor demanda son Maipú, San Bernardo y Puente Alto, con una tasa de crecimiento en sus viajes de $375 \%, 160 \%$ y $46 \%$ respectivamente.

Cabe destacar que en 2001 Puente Alto representaba la comuna con mayor número de desplazamientos en bicicleta, con 2.438 viajes por trabajo y estudio. Las comunas pericentrales del sector sur-Macul, San Joaquín, San Miguel, Cerrillos, La Cisterna, San Ramón, La Granja y La Florida- si bien han experimentado una baja implementación de oferta (ciclovías) en el periodo 20012012, han mantenido o incrementado su demanda en un promedio de $331 \%$. Se estima que esto se debe a un efecto expansivo de lo que ha ocurrido en el sector nororiente de la ciudad (incremento explosivo de la oferta y, con ello, la consolidación de una nueva demanda).
Destaca Maipú, siendo al 2012 la segunda comuna con mayor número de viajes en bicicleta por motivo de trabajo y estudio, con 6.146 desplazamientos cotidianos, siendo superada solo por Las Condes con 7.234. La demanda de Las Condes es nueva, gatillada a partir de la oferta implementada en los últimos 10 años, lo que se refleja en la tasa de crecimiento de $1.341 \%$. Por su parte, la comuna de Maipú ha mantenido e incrementado su demanda antigua en $375 \%$, a pesar de la falta de oferta de ciclovías y su bajo estándar.

Variable origen-destino. Bajo el paraguas que posiciona a la macrozona sursuroriente (grupo de interés) y nororiente (grupo de control) como las que capturan el mayor número de viajes en bicicleta a escala macro (SECTRA, 2013) y de mayor contraste en cuanto a la oferta asignada, se analizan los viajes $\mathrm{OD}^{7}$ de las comunas de mayor representatividad de cada macrozona, siendo Maipú, San Bernardo y Macul representantes del 52\% de los viajes totales de la macrozona sursuroriente, y las comunas del Centro Extendido representantes de un $72 \%$ de la macrozona nororiente.

Con base en la EOD 2012, se georreferencian y grafican de manera conceptual los principales viajes inter e intracomunales de las comunas representativas de ambos grupos en estudio.

\footnotetext{
${ }^{7}$ OD: Origen Destino.
} 


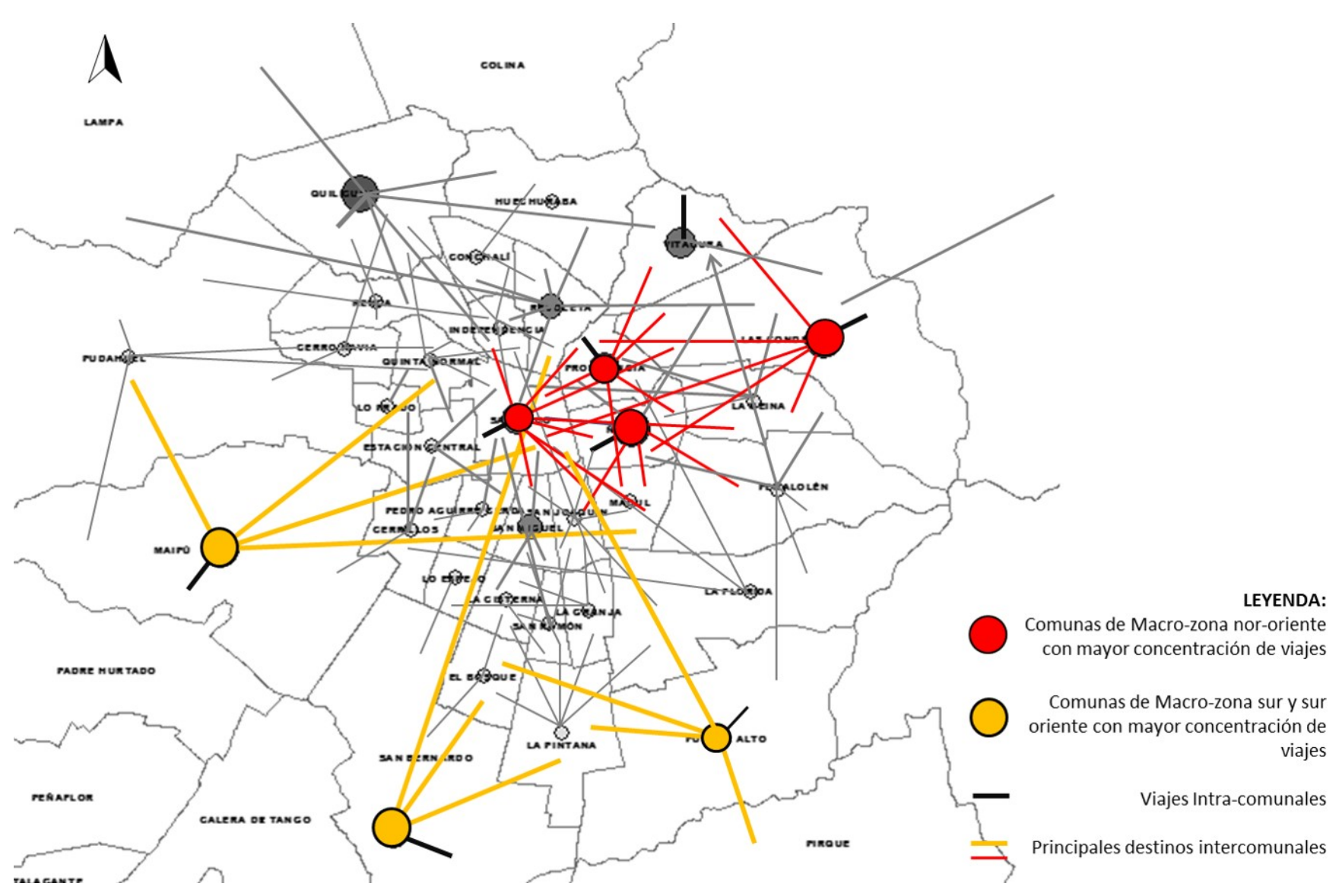

Figura 9. Viajes comunales representativos por macrozona en estudio.

Fuente: Elaboración propia en base a EOD 2012.

El $73 \%$ de los viajes cotidianos en bicicleta de las comunas de Maipú, San Bernardo y Puente Alto se desarrolla a nivel intracomunal, lo que confirma que la mayor eficiencia de este vehículo como transporte cotidiano está en los desplazamientos cuyas distancias van entre los 4 y 7 km (CROW, 2006).

Los viajes intercomunales que se desarrollan en el grupo de control se confinan mayoritariamente al interior del Centro Extendido, en contraposición a las comunas del grupo de interés, donde vemos desplazamientos más largos debido a la necesidad de llegar a los centros de trabajo a costo $\$ 0$ y condicionados a territorios con baja conectividad e inestable frecuencia del transporte.
Factor 3: Eficiencia de la bicicleta en la movilidad cotidiana.

Variable intermodalidad (Metro-Bicicleta). En un sistema de transporte público que ofrece la posibilidad de desplazarse mediante la integración de varios modos (autobús, metro y bicicleta), esta es una variable clave para proponer desplazamientos seguros, cómodos y eficientes. 
La red de metro de la ciudad de Santiago ofrece cobertura territorial bastante heterogénea y no llega a todas las comunas. Lo mismo se observa en la red de buses, a lo que se añade una frecuencia diferenciada según lugar de residencia y GSE. En tal escenario, la combinación de modos usando la bicicleta propia o compartida, pudiendo transbordar con la bicicleta o dejarla detenida en las estaciones de metro, constituiría una real oportunidad de acceso a la ciudad.

El estado de avance de la intermodalidad metrobicicleta, tal como las otras variables analizadas, se observa desigual, mediante un buffer de 500 m y 1000 m en torno a la estación, pudiendo determinar porcentajes de red de ciclovías al año 2016 dentro de dicho buffer.

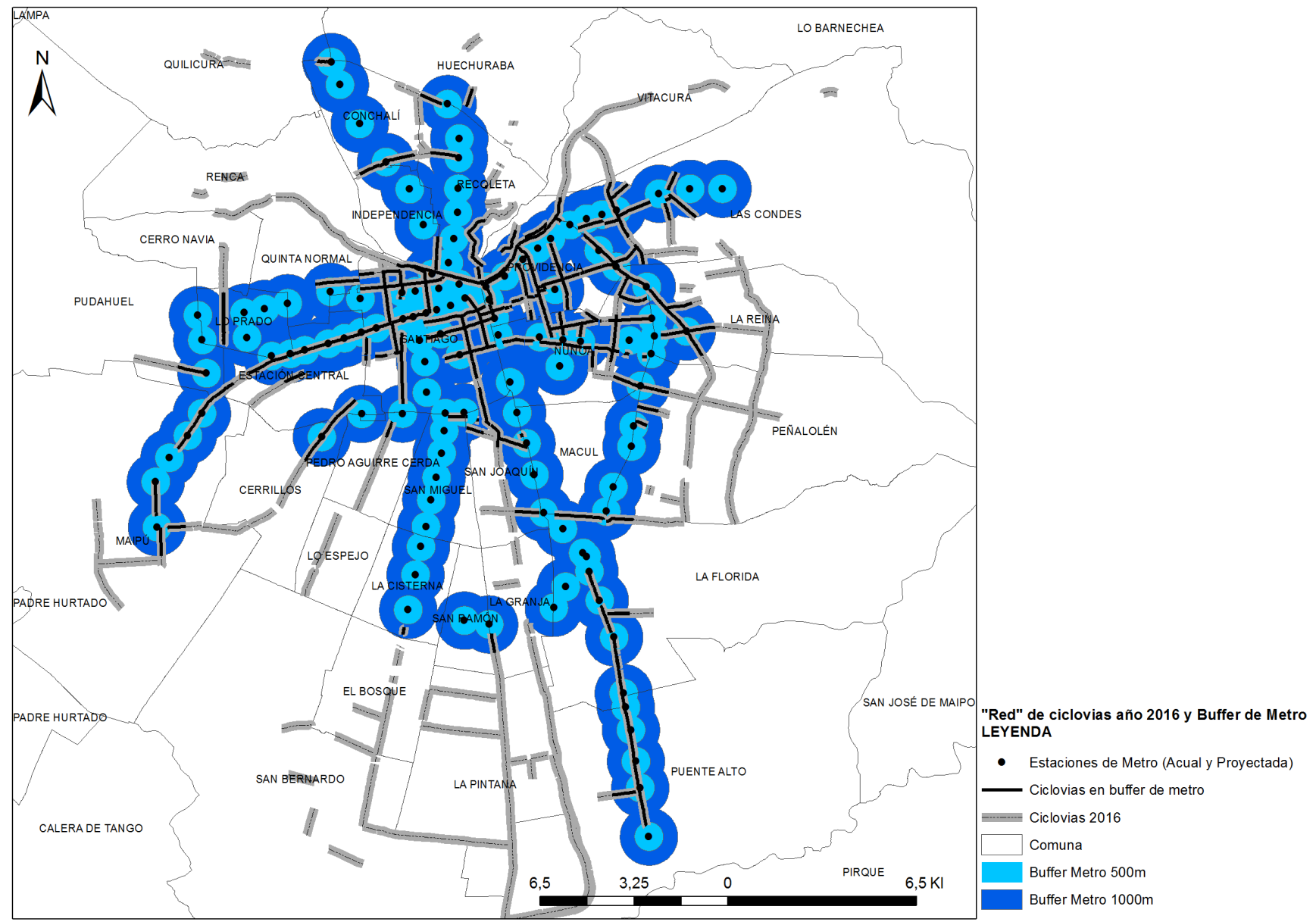

Figura 10. Red de ciclovías año 2016 y buffer de metro (500 y 1000 m).

Fuente: Elaboración propia en base a EOD 2012.

Espacialmente, se reconoce una red de ciclovías cuya estructura principal se desarrolla en sentido norte-sur, al igual que el metro, y por tanto, podemos señalar que la red ciclovial reproduce un acceso desigual a la movilidad y, con ello, a la ciudad. La oferta (ciclovías) debiese responder al dominio de viajes en sentido orienteponiente (SECTRA, 2012) y a la oportunidad de acercar a los habitantes a la intermodalidad con el metro.
Al observar las comunas de interés Maipú y San Bernardo, ambas con alta demanda ciclovial, vemos en Maipú una baja cobertura territorial, tanto de metro como de ciclovías, y sobreposición de la oferta existente (lógica que no responde a la posibilidad de planificar la red ciclovial bajo los conceptos de la intermodalidad), y a San Bernardo sin accesibilidad a metro. 
Por otra parte, al profundizar en cuanto a la sobreconectividad y el acceso a la intermodalidad (metrobicicleta) de los sectores más acomodados y el aislamiento de los sectores más desfavorecidos, se identifica un $65 \%$ de la red de ciclovía del sector nororiente dentro del buffer de metro y solo un $22 \%$ de la red de ciclovía de los sectores sur y suroriente dentro de dicho buffer.

Variable equipamiento de apoyo-biciestacionamientos. La última variable que determina la oportunidad o no de acceder a la MCBT se refiere a la necesidad de contar con estacionamientos para bicicletas como equipamiento de apoyo que permita, por una parte, estacionar este vehículo de manera segura $\mathrm{y}$, por otra, propender a la intermodalidad.

La concentración de biciestacionamientos se desarrolla bajo dos lógicas territoriales preexistentes: se localizan en torno a la red de metro y un $75 \%$ de la oferta está en los sectores más acomodados, situación que profundiza la realidad de desigualdad. El $41 \%$ de las comunas, correspondiente a 14 de estas, no cuenta con biciestacionamientos. De las 20 comunas restantes, las de la macrozona nororiente concentran el $75 \%$ del total de la oferta, correspondiente a 198 biciestacionamientos. El otro $25 \%$ restante -67 biciestacionamientos- se localiza en torno a la red de metro.

A escala macro, se aplicó, mediante estadística, el coeficiente de determinación, denominado $R^{2}$, que corresponde a la correlación o la predicción de una variable por otra. En este caso, en una escala de 0 a $100 \%$, se mide el porcentaje de varianza de las 34 comunas controladas por los indicadores señalados. La varianza explicada indica que en la medida que aumenta una variable, aumenta proporcionalmente la otra, y mide el porcentaje total de comunas donde al aumentar una, aumenta la otra.

Cuando el $R^{2}$ se acerca a 100 , significa que aumenta la infraestructura en relación con el aumento de viajes y, por tanto, existiría mayor proporcionalidad y equidad en el acceso a la oferta de infraestructura de acuerdo con la demanda. Por el contrario, al acercarse a 0 habría mayor disociación entre la localización de la infraestructura y la demanda generada, sea efectiva o potencial.

Tabla 1.

Coeficiente de determinación, denominado $R^{2}$

\begin{tabular}{lc}
\hline Regresión Simple & R2 \\
\hline Km 2016 x Km 2025 & 0,68 \\
\hline Km/viaje 2016 x Km/DDA 2025 & 0,009 \\
\hline Km 2016 x viajes 2012 & 0,18 \\
\hline Km 2025 x DDA POT 2025 & 0,13 \\
\hline
\end{tabular}

Fuente: Elaboración propia con base en EOD 2012.

Una vez realizada la técnica, y al analizar el indicador de $\mathrm{km}$ de infraestructura por viajes actuales versus el de $\mathrm{km}$ de infraestructura por viajes potenciales 2025, se ve que menos del $1 \%$ de la varianza de uno se explica por el otro; por tanto, hay una alteración muy fuerte entre la relación de infraestructura/demanda actual con la de infraestructura/demanda proyectada. Y, derivado de esto, no es posible especificar si esta disociación va a significar ganancia o pérdida de equidad, puesto que para saberlo se necesitaría relacionarlo con indicadores sociales por comuna.
Lo que sí se evidencia y confirma la hipótesis general planteada (ver gráfico siguiente) es que existe una alta desigualdad en cuanto al acceso a infraestructura. Se observa que solamente el $18 \%$ de la infraestructura ( 6 comunas) tiene correlación con los viajes, y por tanto, solo en el $18 \%$ de las comunas en la medida que aumentan los viajes, aumenta la infraestructura. Por consiguiente, en el $82 \%$ de las comunas restantes, no hay relación entre la cantidad de viajes y la proporción de infraestructura. Entre las comunas más desfavorecidas destacan Maipú, San Bernardo, Vitacura y Quilicura, con alta demanda de viajes 
y baja infraestructura. Por otra parte, vemos comunas Recoleta, Providencia y Santiago Centro- con cantidad de viajes análogos y una gran disparidad en la asignación de infraestructura, como reflejo de una distribución ajena a lo requerido por las demandas.

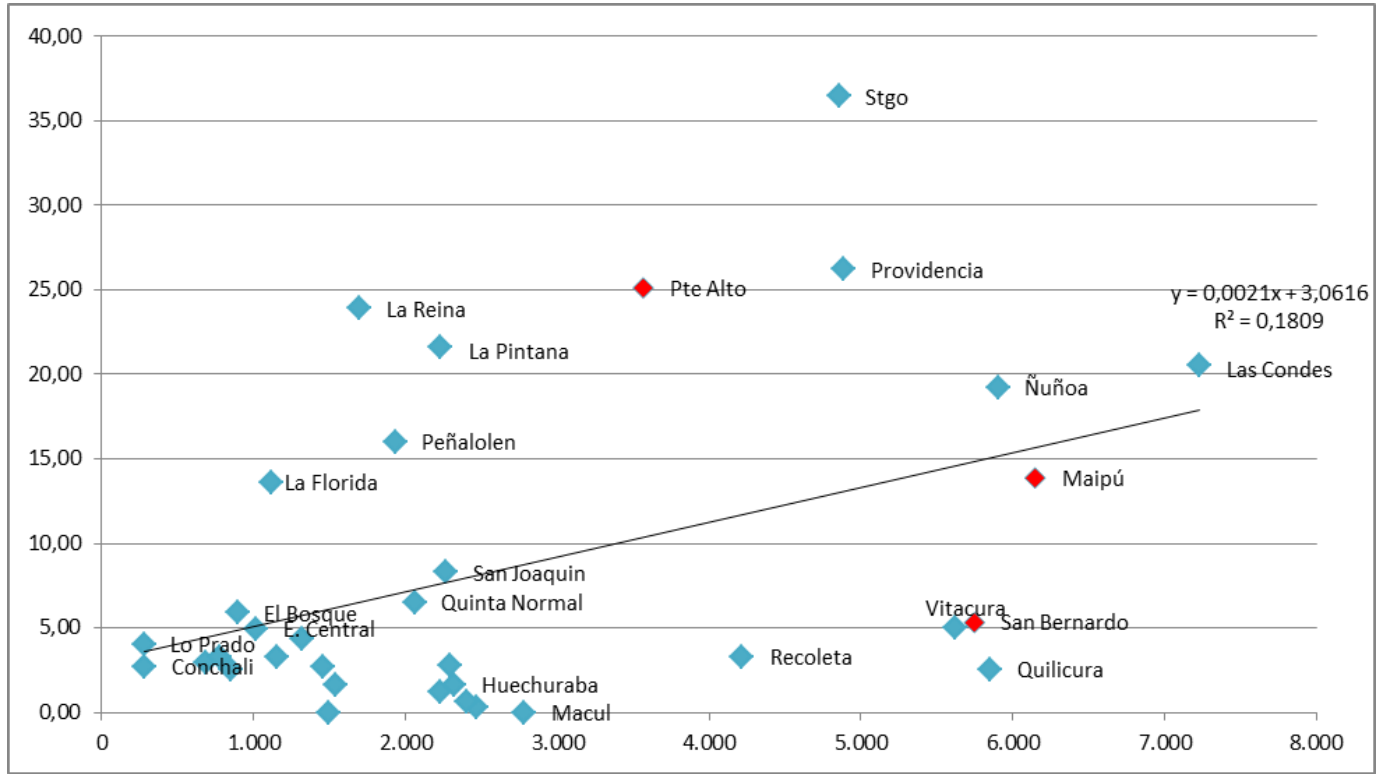

Figura 1. Relación entre km de ciclovías 2016 y demanda de viajes 2012.

Fuente: Elaboración propia con base en EOD 2012.

Cabe señalar que la accesibilidad a la movilidad, en este caso a la MCBT, no se resuelve solo con acceder o no a la oferta, sino también en el reconocimiento de las barreras de accesibilidad a la movilidad relativas a experiencia y calidad de viaje de sus usuarios, barreras que van a determinar la permanencia en el tiempo de dicha movilidad y que son profundizadas en el siguiente análisis.

\section{Estructura de viaje según lugar de residencia - ESCALAS Meso y micro}

Esta sección analiza dos viajes de usuarias de bicicleta. Una de ellas, 40 años, ciclista antigua, es representante del grupo de interés, residente de la comuna de Maipú, sector con alta demanda en el uso de la bicicleta y baja cantidad y estándar de infraestructura. Para ella, la barrera financiera es un importante motivo por el cual ha decidido desplazarse en este vehículo. En cuanto al grupo de control, comunas del Centro Extendido, se analiza el viaje de una ciclista nueva, 29 años, residente de la comuna de Santiago Centro, que representa al sector con mayor oferta de infraestructura cicloinclusiva y menor demanda hasta la EOD 2006, situación que se revierte en la última EOD 2012, como ya se señaló.

La caracterización de los dos casos de estudio se aborda en base al análisis y el contraste de las siguientes variables: Barreras de viaje y su expresión en el espacio público, experiencia de viaje y calidad de viaje.

A continuación, se adjunta la especialización del viaje en bicicleta de las ciclistas antigua y nueva, con el propósito de graficar y caracterizar barreras, experiencias y calidad del recorrido de ambas. 

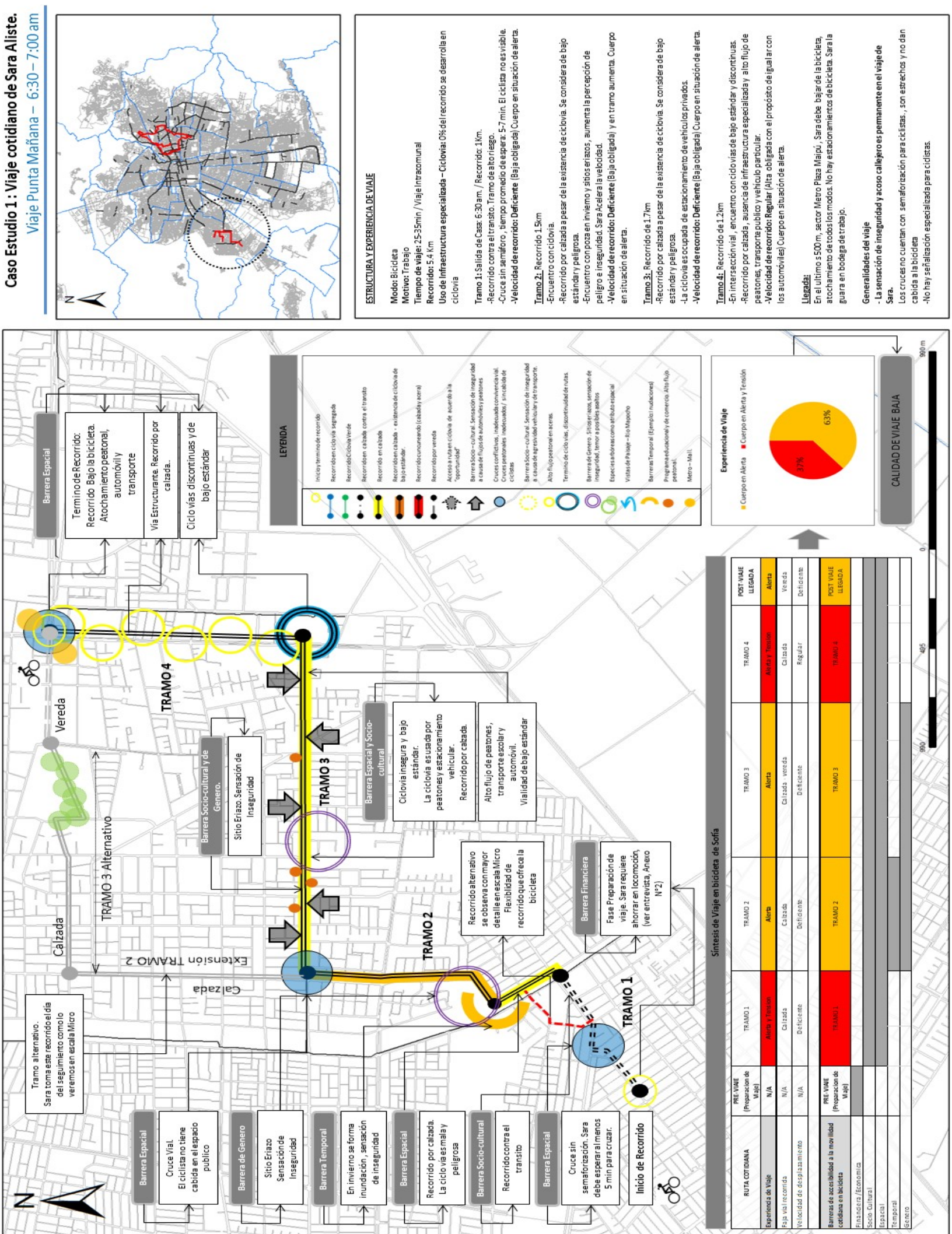

Figura 2.Especialización Viaje PM de ciclista antigua.

Fuente: Elaboración propia. 

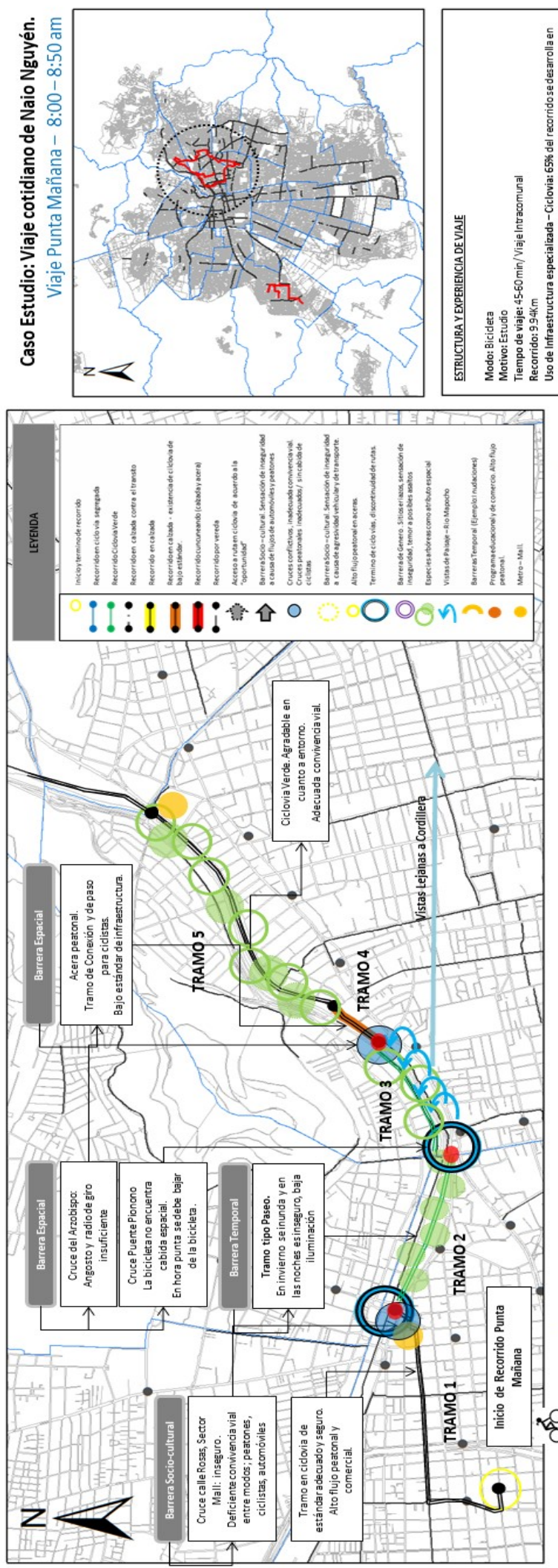
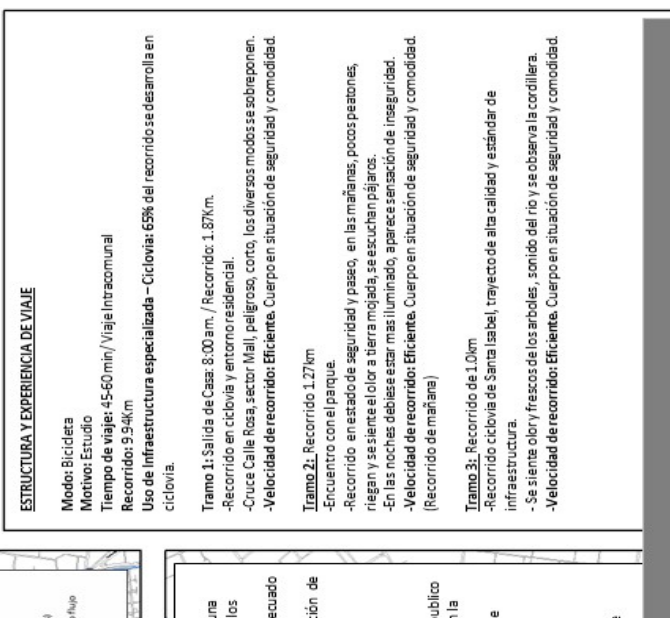

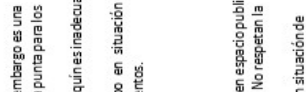

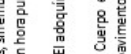

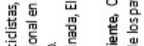
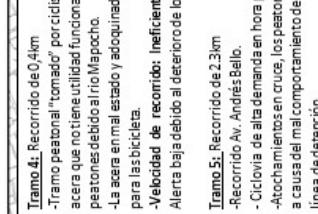

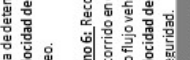
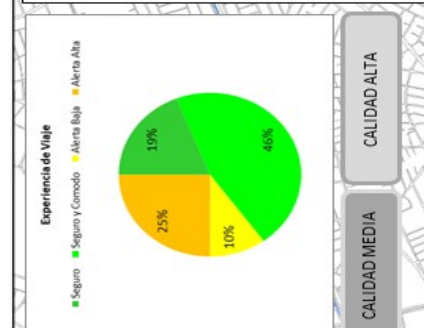

12
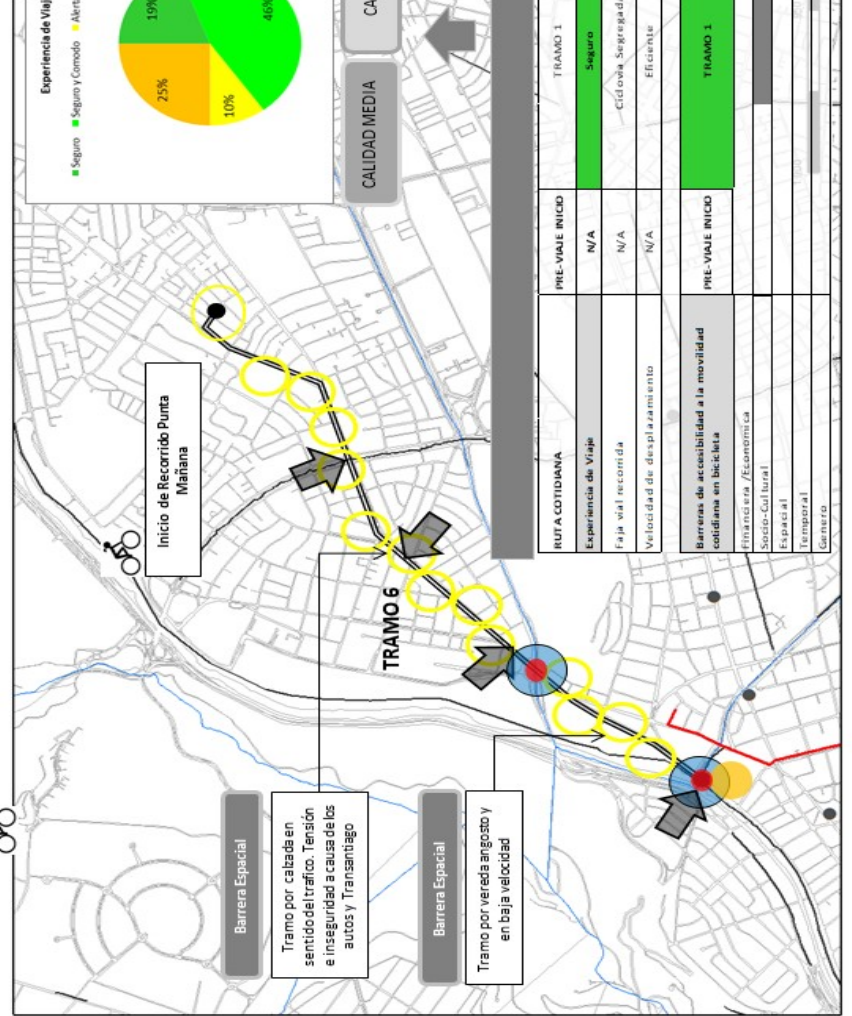

Figura 13. Especialización viaje PM ciclista nueva.

Fuente: Elaboración propia. 
Lo primero que se reconoce en los dos casos de estudio ${ }^{8}$ expuestos es una movilidad cotidiana en bicicleta, que aborda espacios, tiempos y experiencias diversas según el momento y el usuario que lo realice. En general, se observa un primer momento -previaje-, relacionado con los aspectos asociados a la preparación e interdependencias del desplazamiento. Luego se identifican tramos de viaje, sujetos a diferentes distancias, dinámicas, estándares, barreras y experiencias, que inciden directamente en el "estado del cuerpo", dada la relación directa que establece la bicicleta entre el cuerpo y el entorno urbano -clima, geografía, sonidos, esfuerzo físico e interacción con los demás modos de transporte, entre otros-. Finalmente, un último momento del desplazamiento -posviaje- que corresponde a la capacidad de "llegar" y estacionar la bicicleta de manera segura y confiable. Cada tramo de viaje, observado en forma diferenciada en los casos de estudio, se estructura y caracteriza según las distintas barreras que cada ciclista urbano debe subvertir, ideando distintas estrategias de desplazamiento y determinando diferentes experiencias y calidades de este, y que en conjunto con los casos de estudio se definieron como: Alerta y Tensión, Alerta Alta, Alerta Baja, Cómodo y Cómodo Seguro.

La primera barrera analizada fue la financiera. Para la ciclista antigua, representa la primera dificultad de viaje, siendo el ahorro en transporte un aspecto importante de abordar. Por tanto, el costo cero tiene alta incidencia en la decisión de movilizarse en bicicleta, decisión que se profundiza como efecto de la mala calidad y baja frecuencia del transporte público disponible en Maipú. Por su parte, la ciclista nueva, residente del Centro Extendido, no muestra preocupación por la variable económica o, al menos, no en el marco de incidir en la decisión de usar o no un modo de transporte. La barrera espacial es determinada principalmente por la existencia o no de infraestructura cicloinclusiva, señalización y equipamiento de apoyo y su estándar. Aunque existe una alta diferencia en cuanto a cantidad, estándar y estado de conservación de la infraestructura según lugar de residencia, más relevante fue observar las diferenciadas implicancias que ello conlleva según edad, experiencia y género.
La ciclista antigua, con alta experiencia en ciclismo urbano, señala no tener mayor conflicto con la inexistencia de ciclovías en sus rutas; por el contrario, logra mayor eficiencia y accesibilidad (tiempo-distancia) viajando en calzada. Otros casos de estudio de la comuna de Maipú, Carlos y Martín, ambos de tercera edad y con más de 10 años de ciclismo urbano, manifiestan sentir vulnerabilidad y miedo al manejar por las calzadas y, por tanto, viajan "cuncuneando" entre calzada y acera. Ambos reconocen el impacto económico que tendría un accidente en sus presupuestos $y$, debido a ello, prefieren ir a una velocidad deficiente, pero sentir mayor seguridad en el viaje. En la otra cara de la moneda, vemos el caso de la ciclista nueva, con un promedio de $45 \%$ de recorrido en ciclovías de estándar adecuado y seguro. En su viaje destacan las ciclovías de calle Rosas, Santa María y Andrés Bello, infraestructura que además de proporcionar seguridad, ofrece a sus usuarios comodidad y disfrute en la movilidad.

En cuanto a la barrera sociocultural, esta se expresa como la de mayor conflictividad y dominio. Bajo la muestra desarrollada, y en base a lo observado en terreno, pareciera que la baja cultura vial se concentra más intensamente entre los modos motorizados (camiones y transporte público), mientras que en el grupo de control se observa con mayor intensidad entre los ciclistas nuevos. La ciclista antigua manifiesta una permanente convivencia con la falta de cultura vial por parte de los modos motorizados, que no solo no respetan velocidades, semáforos y normas del tránsito, sino que, además, muestran continuamente agresión y acoso callejero. En el sector de control observamos reiteradas veces y mediante diversas prácticas una importante falta de cultura vial de los ciclistas nuevos: no respetan semáforos, espacios peatonales ni líneas de detención y adelantan sin precaución, entre otras conductas.

En relación a la barrera de género y de temporalidad, se observa a escala micro, dinámicas cotidianas de ambas ciclistas, la nueva y la antigua, asociadas a los procesos de acceder a la movilidad en bicicleta -interdependencias familiares, motivos, barreras de accesibilidad $y$ experiencias de viaje-, que confirman la movilidad como una multiplicidad de obstáculos que enfrentan las

\footnotetext{
${ }^{8}$ En total, son siete los casos de estudio de la investigación de tesis de magíster (Salas, 2018).
} 
personas en forma cotidiana, determinando parte de la calidad de vida de estas y corroborando también una movilidad que incide de manera desigual en los procesos de exclusión social, principalmente marcados por el lugar de residencia y GSE. Lo primero que destaca son los disímiles motivos por los que ambas usuarias deciden retomar la bicicleta como modo de transporte. Mientras la ciclista antigua lo hace por motivos económicos (ahorro) y para sobrellevar de mejor forma una depresión postseparación, la ciclista nueva la retoma con la finalidad de mejorar su calidad de vida y transformar su viaje en su momento de relajo y deporte.

Para la ciclista antigua, las alternativas de transporte a las que podría acceder -micro o colectivo- representan una solución cara y deficiente dada su irregular frecuencia y alta congestión vial, mientras que para la ciclista nueva, las alternativas de transporte -micro o metro- representan una posibilidad viable y factible en términos de costo y tiempo, pero bastante congestionada en $\mathrm{HPM}^{9}$. Por tanto, mientras para la ciclista antigua moverse en bicicleta es una oportunidad de acceder a la ciudad, para la nueva representa otra alternativa de viaje.

En cuanto a las barreras de accesibilidad a la movilidad, ambas ciclistas enfrentan un continuo aparecer $y$ desaparecer de estas. Sin embargo, para la ciclista antigua, interactuar con barreras financieras, físicoespaciales, socioculturales, temporales y de género determina un viaje cuya accesibilidad a los bienes y servicios se torna muchas veces hostil, conflictiva e insegura.

El viaje de la ciclista antigua está marcado especialmente por su condición de género: acoso verbal, hombres que compiten con ella (ciclistas que la adelantan), sensación de inseguridad y calles que no puede transitar, lo que la lleva a desarrollar estrategias tales como usar una única ruta para que la puedan encontrar en caso de posibles asaltos u otros. Su desplazamiento expresa una movilidad cotidiana que no solo reproduce patrones asociados a la estructura física de la bicicleta sino también manifiesta una condición de poder entre hombre y mujer. La ciclista nueva, por su parte, declara no haber observado desigualdad en cuanto a condición de género al acceder a la movilidad, a excepción de algunas limitaciones de vestuario y mayor vulnerabilidad al transitar de noche por calles mal iluminadas.

En cuanto a las barreras socioculturales, ambas ciclistas experimentan una baja cultura vial. En la ciclista antigua domina la falta de cultura vial y agresividad de los modos motorizados, como alta velocidad, insultos sexuales y "tirar el auto encima" entre otros. Por su parte, en el viaje de la ciclista nueva, se observa con mayor frecuencia deficiencias y faltas a las normas viales por parte de los nuevos ciclistas: cruzar con luz roja, pelear por el espacio, desplazarse por aceras a pesar de contar con ciclovías y detenerse por sobre la línea demarcada, entre otros.

Las barreras espaciales, principalmente ausencia de ciclovías, tienen disimiles impactos sobre las ciclistas urbanas. Para la ciclista antigua resulta cómodo viajar en calzada, dada su experiencia, lo que le permite tomar la velocidad que requiere; sin embargo, también es consciente de su vulnerabilidad y de los peligros a los que se expone a causa de la baja cultura vial que experimenta por parte de los otros modos. La ciclista nueva realiza cerca del $65 \%$ de su viaje en ciclovías de adecuado estándar técnico y paisajístico -Rosas, Santa María y Andrés Bello-, y debido a ello, el 65\% de su recorrido es seguro, confiable y eficiente, mientras que la ciclista antigua, cuya demanda y necesidad de usar la bicicleta como modo de transporte es mayor que la de la ciclista nueva, cuenta con $0 \%$ de $\mathrm{km}$ de ciclovías en su recorrido. Sin embargo, ambas coinciden en que el desplazamiento por calzada es más eficiente y por tanto la ciclovía no es la única ni la mejor solución a una movilidad cicloinclusiva, pues dependerá de los objetivos y necesidades locales, disponibilidad de espacio, jerarquización y cultura viales, entre otros factores.

\section{CONCLUSIONES}

Respecto al análisis macro y con la finalidad de especificar la desigualdad develada y con ello probar la hipótesis, las 6 variables analizadas a escala macro $-\mathrm{km}$ de infraestructura (actual y proyectada), demanda (actual y potencial), intermodalidad y equipamiento de apoyo-

\footnotetext{
${ }^{9}$ HPM: Hora Punta Mañana.
} 
visibilizaron una alta desigualdad de acceso a la MCBT según lugar de residencia y GSE. Asimismo, mostraron un transporte que propone constituirse como un modo sustentable, y que en Santiago está siendo implementado bajo las lógicas de un sistema de transporte preexistente, profundizando aún más las desigualdades.

Se confirma la hipótesis planteada. Existe una alta desigualdad en cuanto al acceso a la infraestructura, viajes en bicicleta por motivo de trabajo y estudio de la EOD 2012 versus la disponibilidad de infraestructura neta, $\mathrm{km}$ de ciclovías 2016 . Se evidencia que solamente el $18 \%$ de la infraestructura (6 comunas) tiene correlación con los viajes, y por tanto solo en el $18 \%$ de las comunas en la medida que aumentan los viajes aumenta la infraestructura. También podemos concluir que, en general, todas las comunas aumentan su infraestructura al año 2025, pero de manera desigual. Solo en 4 comunas pericentrales la infraestructura futura aumentaría de manera proporcional a la actual, en caso de consolidarse el PMCGS. En cuanto a la cantidad de infraestructura implementada en los últimos 15 años, las comunas del cono oriente son las más favorecidas y mantendrían su posición de privilegio al 2025.

A escala meso y poniendo el foco de interés en el sector sur de la ciudad -sectores de más bajos recursos, largos desplazamientos pendulares, altos costos de transporte y largos tiempos de viaje-, se concluye que la bicicleta constituye una necesidad más que una opción de transporte. Esto se confirma en una demanda que se ha mantenido constante en los últimos 15 años, experimentando en algunos sectores un crecimiento de hasta un $40 \%$ a pesar de la falta de oferta y, por tanto, se reconoce un ciclista urbano antiguo. A escalas meso y micro se establece una movilidad diferenciada según edad y género, lo que se profundiza según lugar de residencia y GSE, condición que respalda la idea de que cada territorio posee distintas dinámicas, cultura, barreras y requerimientos, y por tanto, demanda una respuesta diferenciada por parte de la planificación.

Metodológicamente, se identificaron tramos de viajes, cada uno sujeto a diferentes distancias, dinámicas, estándares, barreras y experiencias, que en el caso de la movilidad en bicicleta inciden directamente en el estado del cuerpo debido a la directa relación que se establece entre el cuerpo y el entorno urbano. Asimismo, cada tramo se estructura y caracteriza según las barreras que cada ciclista urbano debe subvertir, ideando estrategias que condicionan la experiencia y la calidad de su viaje. Parte de la metodología vivencial permitió identificar, en conjunto con los ciclistas, cambios en el estado del cuerpo según cada tramo de recorrido.

Contrastando los dos casos de estudio, vemos que para algunos la existencia de ciclovía (barrera espacial) representa seguridad y confiabilidad en el recorrido, mientras que para otros significa atochamientos y pérdida de eficiencia en la accesibilidad (tiempo-distancia). Lo mismo ocurre al observar la barrera económica: la bicicleta, para los casos del sector sur, representa una oportunidad de acceder a los bienes y servicios de manera más económica, mientras que para los ciclistas del cono oriente significa solo otra alternativa de viaje. La barrera sociocultural corresponde en forma transversal a ambos sectores. Se puede concluir que la baja calidad de cultura y convivencia vial afecta e incide en la experiencia y la calidad de viaje de todos los casos estudiados, experimentado barreras asociadas a la agresividad entre modos de transporte -asaltos, acoso callejero en la comuna de Maipú- y una marcada falta de cultura vial en los ciclistas nuevos del cono oriente de la ciudad. En cuanto a la barrera de género según lugar de residencia, aunque esta variable no fue de interés de la autora en los inicios del estudio, sí cobra relevancia y se expresa de manera diferenciada a través de una marcada desigualdad al momento de acceder a la movilidad urbana, pudiendo la movilidad en bicicleta con enfoque de género ser materia de otra investigación.

Se confirma un acceso a la movilidad en bicicleta altamente desigual, marcado por iniciativas y disponibilidad de recursos locales más que por una planificación de escala metropolitana integral y que, observado a escalas locales, reproduce y profundiza experiencias diferenciadas altamente desiguales que, inscritas en el marco de la movilidad de las personas, finalmente construye estándares de calidad de vida diferenciados.

Bajo la oportunidad que representa la bicicleta como modo de transporte capaz de mitigar y descongestionar en parte la ciudad de Santiago, y con la finalidad de incrementar su uso, es necesario que la planificación asociada a la movilidad incluya objetivos y criterios de 
mitigación de desigualdad según lugar de residencia y GSE, en correlación con el análisis de la demanda potencial de personas que se espera se desplazarían por razones de trabajo y estudio. Y con ello, generar un plan maestro que zonifique sectores críticos de atención, determinados en base a una alta demanda potencial y un nivel de infraestructura deficiente en cantidad y calidad, lo que finalmente impide la migración de modos motorizados a bicicletas y su permanencia en ella.

A escala meso y micro, es necesario profundizar y complementar las metodologías tradicionales de transporte con estudios de tipo cualitativos que permitan conocer y caracterizar las dinámicas y barreras de la movilidad que en general se mantienen invisibilizadas en la planificación actual, soslayando aspectos de la demanda que permitirían planificar y proyectar de manera más correlacionada a los requerimientos particulares de cada territorio y grupo de ciclistas.
Entre las recomendaciones de políticas que se consideran necesarias en base a lo observado en este estudio, destaca la de mitigar la actual desigualdad de viajes en bicicleta por comuna con una elevada correlación con el nivel de ingreso de cada una. Ello requiere planes metropolitanos basados en datos disponibles en la EOD que busquen objetivos de equidad. Otra sugerencia que emana de esta investigación es la de revisar sistemas de diseño y evaluación de proyectos de ciclovías de acuerdo con las características de los trayectos, barreras de movilidad, experiencias de viaje, convivencia y seguridad vial. Asimismo, se observa y se indica la necesidad de desarrollar manual de ciclovías con perspectiva de género, que considere las vivencias de más mujeres, de manera de recoger otras brechas importantes de acceso a la bicicleta y no solo las de tipo socioeconómico [B] 


\section{Referencias}

Banco Mundial. (2017). Transporte. Panorama General. Recuperado de https://www.bancomundial.or g/es/topic/transport/overview

Cebollada, À. (2008). Equidad social en movilidad: reflexiones en torno a los casos de Barcelona y Lima. Scripta Nova, Revista electrónica de geografía y ciencias sociales, (XII),270. http://www.ub.edu/geocrit/sn/sn-270/sn-27047.htm

CROW (2006). Manual de diseño para el tráfico de bicicletas. Holanda: CROW, Ede.

French-Davis, López y Arriagada. (2013). Chile Urbano hacia el siglo XXI. Investigaciones y reflexiones de política urbana desde la Universidad de Chile. Crecimiento desigual económico y urbano: desafíos de políticas pro equidad para las ciudades de las próximas décadas. (pp.149-159) Santiago de Chile: Universitaria.

Gobierno. (2015). Informe de la Comisión Asesora Presidencial Pro Movilidad. Santiago. Recuperado de http://www.mtt.gob.cl/promovilidad/informe-finalpromovilidad

GORE. (2012). Investigación, factiblidad y gestión de concesión de bicicletas públicas. Santiago. Recuperado de https://www.gobiernosantiago.cl

Gutiérrez, A. (2012). ¿Qué es la movilidad? Elementos para (re) construir las definiciones básicas del campo del transporte. Revista Bitácora Urbano Territorial, 21, 61-74. https://www.redalyc.org/articulo.oa?id $=74826255011$

Hall, P. (1996). Ciudades del mañana. Historia del urbanismo en el siglo XX. Barcelona: Serbal, Colección La Estrella Polar.

Jirón, P. (2007). Implicancias de género en las experiencias de movilidad cotidiana urbana en Santiago de Chile. Estudios de la mujer, 12(29), 173198.
Jirón, P. (2012). La importancia de la experiencia de la movilidad en la planificacion del transporte. Aprendizajes de Santiago de Chile. En Dávila, J. D. (Compilador), Movilidad urbana y pobreza: aprendizajes de Medellín y Soacha, Colombia (pp.23-30). Londres: UCL. Recuperado de http://discovery.ucl.ac.uk/1371083/

Jirón, P. (2013). Atravesando la espesura de la ciudad: vida cotidiana y barreras de accesibilidad de los habitantes de la perifieria urbana de Santiago de Chile. Revista de Geografía Norte Grande, 56, 53-74. https://doi.org/10.4067/s071834022013000300004

Lynch, K. (1998). La imagen de la ciudad. Barcelona. España: Gustavo Gili.

Miralles-Guasch, C. y Cebollada, Á. (2003). Movilidad y Transporte. Opciones políticas para la ciudad. España: Fundación Alternativas.

PNDU. (2014). Política Nacional de Desarrollo Urbano. Santiago. Recuperado de cndu.gob.cl/politicanacional-de-desarrollo-urbano/

PNDU. (2015). Política Nacional de Desarrollo Urbano. Santiago. Recuperado de cndu.gob.cl/politicanacional-de-desarrollo-urbano/

Rodríguez, J. (2008). Movilidad cotidiana, desigualdad social y segregación residencial en cuatro metrópolis de América Latina. Eure, 34(103), 49-71. http://dx.doi.org/10.4067/S0250$\underline{71612008000300003}$

Salas, M.R. (2018). El uso de la Bicicleta : reproductor del acceso desigual a la movilidad cotidiana urbana : visibilizar al ciclista tradicional que reside y se desplaza en la periferia sur de la Metrópolis; una oportunidad hacia ciudades más inclusivas : Caso de Santiago (Tesis de postgrado). Uniersidad de Chile, Santiago de Chile. Recuperada de http://repositorio.uchile.cl/handle/2250/151962 
SECTRA. (2006, 2012). Encuesta Origen Destino. Santiago: GORE. Recuperado de www.mtt.gob.cl/archivos/10194

SECTRA. (2012). Encuenta de Origen Destino. Santiago. Chile. Recuperado de www.sectra.gob.cl/encues tas movilidad/encuestas movilidad.htm
SECTRA. (2013). Análisis y evaluación del Plan Maestro de Ciclovías del Gran Santiago. Santiago. Chile. Recuperado de www.sectra.gob.cl/biblioteca/detal le1.asp?mfn $=3086$

SECTRA. (2014). Análisis y evaluación del Plan Maestro de Ciclovías del Gran Santiago. Santiago. Recuperado de www.sectra.cl/biblioteca/detalle1.asp? $\mathrm{mfn}=3086$ 